\title{
Nonlinear Control of a Batch Polymerization Reactor: an Experimental Study
}

\author{
Masoud Soroush and Costas Kravaris \\ Dept. of Chemical Engineering, The University of Michigan, Ann Arbor, MI 48109
}

\begin{abstract}
This work studies the experimental application of the globally linearizing control $(G L C)$ method to a batch polymerization reactor. The nonlinear controller is implemented on a microcomputer to start up the reactor and then track a precalculated optimal temperature profile. The reactor temperature is controlled by manipulating two coordinated inputs: power to an electrical heat and cooling water flow rate. $A$ reduced-order observer is used to estimate the concentration of initiator and monomer. Systematic tuning guidelines are proposed for the nonlinear control method. The experimental results show the excellent servo and regulatory performance of the nonlinear controller in the presence of modeling and observer initialization errors and active manipulated input constraints. Furthermore, in comparison to a conventional PID controller, the performance of the nonlinear controller is significantly superior, and its tuning is much easier.
\end{abstract}

\section{Introduction}

Polymerization reactors play a key role in polymer engineering, and the importance of their effective control is well recognized in the polymerization literature (for example, Amrehn, 1977; Elicabe and Meira, 1988; MacGregor, 1986; Ray, 1986, 1992; Tirrell et al., 1987). A major characteristic of polymerization reactors is their complex nonlinear behavior (Ray, 1986; Baillagou and Soong, 1985a). In particular, Ray and coworkers (Schmidt and Ray, 1981; Hamer et al., 1981; Schmidt et al., 1981) have shown theoretically and experimentally the existence of both S-type and isola-type steadystate multiplicities, parametric sensitivity and limit cycles for free-radical polymerization of some monomers in continuous stirred-tank reactors. Due to the complex nonlinear nature of polymerization reactors,

- Control of polymerization reactors has always been a challenging task

- The need for nonlinear control has been recognized in the polymerization literature (for example, Ray, 1986; MacGregor, 1986).

Polymerization reactor models have been used extensively to test the performance of a variety of control techniques through simulations. However, only a very limited number of experimental control studies have been reported in the literature. Adaptive, model-predictive and other conventional controllers have been tested experimentally, primarily in batch polymerizations (Bejger et al., 1981; Inglis et al., 1991; Ponnuswamy et al., 1987; Tirrell and Gromley, 1981; Tzouanas and Shah, 1989).

Many polymeric products are low-volume specialty materials, frequently copolymers, designed to perform a specified function. Consequently, the most prevalent mode of polymerization is in batch reactors, which allow for great flexibility. The mode of operation of batch processes is intrinsically dynamic; there is no steady state for a batch process. The process gain and time constants vary with time usually within a very wide range during a batch cycle. Because of these features of batch processes, their effective control demands controllers that are able to provide good dynamic response over the entire operating range of the process variables. This contrasts with the precise control over a small range that is required in many continuous processes. Therefore, if linear controllers are employed for batch processes, they need to be retuned frequently during a batch cycle. The retuning is performed to enhance the speed of closed-loop response over the wide range of operation without the danger of instability. Indeed, frequent online retuning of linear controllers (such as conventional PIDs) for the tight control of batch processes is a common practice in industry (Juba and Hamer, 1986; Ray, 1986).

The above features of polymerization reactors and batch processes necessitate the use of nonlinear control for this experimental study, which involves both batch operation and 


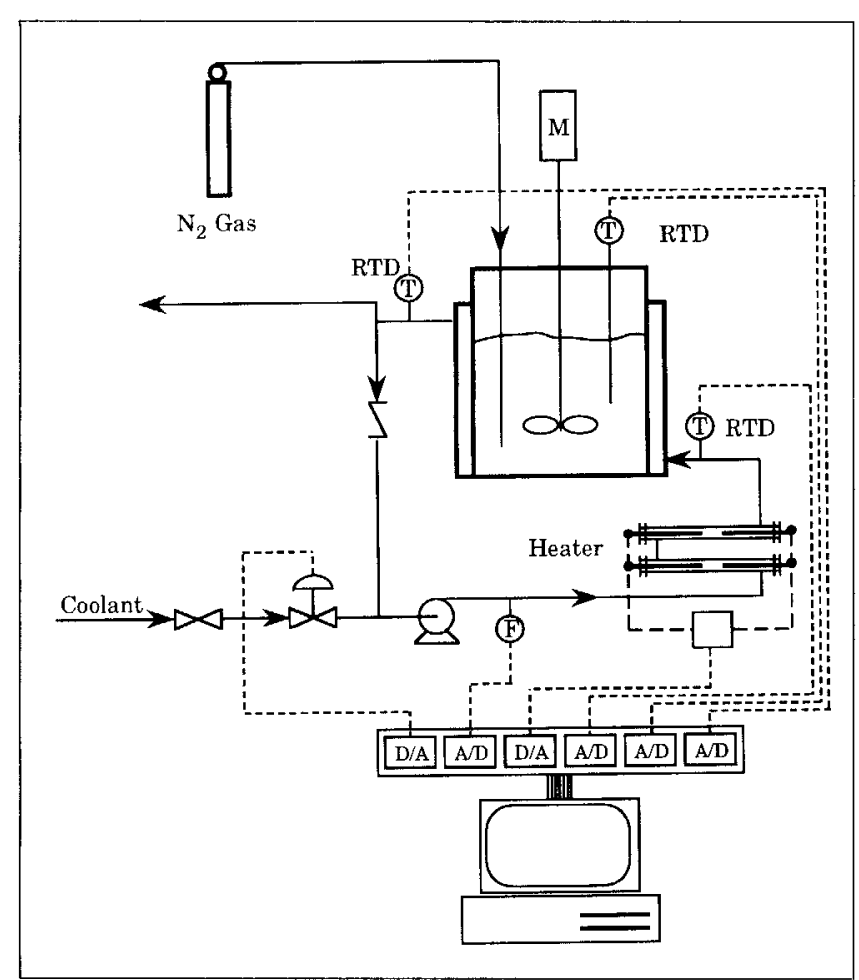

Figure 1. Experimental system.

polymerization reactions.

During the $80 \mathrm{~s}$, significant advances were made in the area of nonlinear control, primarily within the differential geometric framework. Not only the system theoretic properties of nonlinear systems are now well understood (Nijmeijer and van der Schaft, 1990), but also controller design techniques are available, like the globally linearizing control (GLC) method (Kravaris and Chung, 1987; Kravaris and Soroush, 1990). Until 1991, applications of the newly emerged nonlinear control techniques in chemical engineering were restricted to numerical simulations, and the lack of experimental studies was evident. During 1991, a few experimental studies were reported in the literature. Levine and Rouchon (1991) applied a disturbance decoupling control technique to an industrial binary distillation column. Wright et al. (1991) used a nonlinear control law based on a notion of state/output linearization to control a $\mathrm{pH}$ process. Nakamoto and Watanabe (1991) used the GLC to control level and temperature, and level and $\mathrm{pH}$ in a tank.

In this experimental study, the GLC method is implemented to control the temperature of a batch polymerization reactor, in which solution polymerization of methyl methyacrylate (MMA) takes place. The initiator and solvent are azo-bisisobutyronitrile (AIBN) and toluene, respectively. This work is the first experimental study, in which a nonlinear modelbased control method is applied to a polymerization reactor. Some preliminary results of this study were presented by Soroush and Kravaris (1991).

Table 1. Some Parameters of Experimental System

$\begin{aligned} T_{c w} & =2.797 \times 10^{2} \mathrm{~K} & T_{\infty} & =2.932 \times 10^{2} \mathrm{~K} \\ c_{w} & =4.2 \times 10^{0} \mathrm{~kJ} \cdot \mathrm{kg}^{-1} \cdot \mathrm{K}^{-1} & \rho_{w} & =1.0 \times 10^{3} \mathrm{~kg} \cdot \mathrm{m}^{-3} \\ \boldsymbol{P}_{\max } & =3.13 \times 10^{0} \mathrm{~kJ} \cdot \mathrm{s}^{-1} & F_{c w_{\max }} & =2.55 \times 10^{-4} \mathrm{~m}^{3} \cdot \mathrm{s}^{-1}\end{aligned}$

This article first describes the experimental system and develops its mathematical model. Then, the results of dynamic optimization of the batch reactor (the optimal loading and operating conditions) are presented, as well as the estimation of the process parameters of the experimental system. Subsequently, the GLC synthesis framework is reviewed briefly, and then systematic tuning guidelines for low relative-order SISO processes are proposed. A nonlinear controller within the GLC framework is then synthesized for the experimental system, followed by a discussion of the issues involved in the on-line implementation of the control law. Finally, after examining the validity of the kinetic model, the performance of the nonlinear controller is examined under different levels of process information and is compared with the performance of a PID controller.

\section{Experimental System}

Figure 1 depicts a schematic diagram of the batch reactor system. The reactor is a $3-\mathrm{L}$ jacketed glass vessel. The reacting mixture is mixed by a multipaddle agitator, which is connected to a constant RPM motor.

The computer is a DTK TECH-1000 which is connected to a DASH-16 analog/digital I/O expansion board and a DDA06 digital/analog I/O expansion board (both from MetraByte Corp.). These two expansion boards use 12-bit converters; therefore, the digital signals are 12-bit. The analog signals from the measuring elements are amplified and conditioned by MB32 (4-20 mA/0-5 V) modules and MB34 $\left(0-100^{\circ} \mathrm{C} / 0-5 \mathrm{~V}\right)$ modules (all from MetraByte Corp.). The data acquisition software is ASYST from Asyst Software Technologies, Inc.

The heating/cooling system of the reactor consists of an electrical heater, circulating tubes, a pneumatic control valve, a flowmeter, a circulating pump, temperature sensors (two 0 $100^{\circ} \mathrm{C}$ Resistance Temperature Detectors [RTD], accuracy: $\pm 0.2^{\circ} \mathrm{C}$ ). The reactor temperature is measured by a RTD of the same type. The circulating pump maintains a constant jacket-side heat-transfer coefficient for all possible conditions. The volumetric flow rate of the water inside the jacket is measured by a Compak flow transmitter (from Signet Industrial, Inc.) which outputs a 4-20-mA signal proportional to the flow rate.

In this heating/cooling scheme, the inlet flow rate of cooling water $\left(F_{c w}\right)$ and the input power to the heater $(\boldsymbol{P})$ are the manipulated inputs. The inlet coolant flow rate $\left(F_{c w}\right)$ is adjusted by a pneumatic control valve in proportion to its inlet air pressure which is regulated by a current-to-pressure transducer (4-20-mA/3-15 psig). The heater power is adjusted by a solid-state relay (SSR) which is connected to a PCM driver module (both from Omega Engineering, Inc.). The driver module allows simple conversion of the ON/OFF SSR to a proportional power regulator. Therefore, the average power to the heater is proportional to the input $4-20-\mathrm{mA}$ analog signal to the driver module. The electrical heater consists of four high-watt density cartridge heaters. Other specifications of the experimental system are given in Table 1.

\section{Dynamics of the control elements}

The dynamics of the control elements (the control valve, the RTD's, the control valve pressure transducer, and the heater) 
Table 2. Free Radical Reaction Mechanism

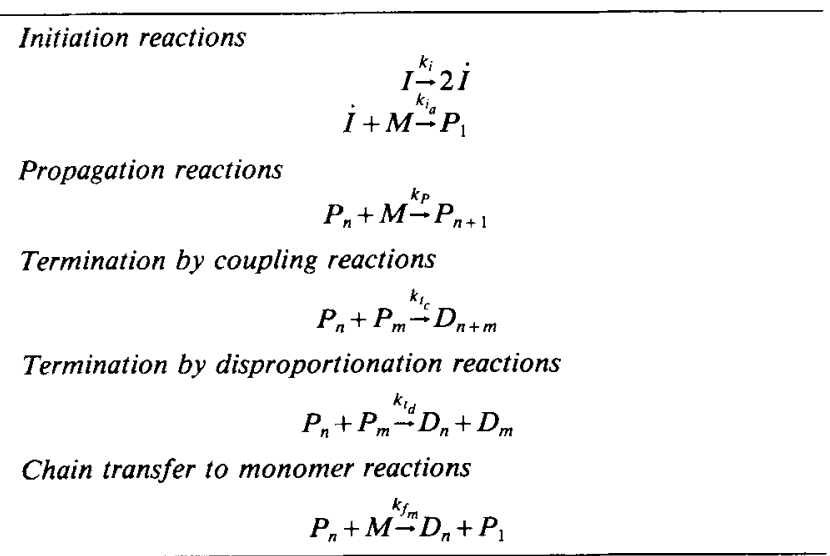

are very fast compared to the dynamics of the reactor and the jacket. Therefore, these dynamics will be neglected in the model development of the system. A study of the steady-state input/ output behavior of these elements showed that the heater (signal/power), the RTD's (temperature/signal) and the pressure transducer (signal/air pressure) are linear. Therefore, the signals from or to these elements are calibrated by linear equations. However, the steady-state behavior of the air-to-close control valve (air pressure/flow) is not linear and can be represented by a quadratic equation. This nonlinearity is accounted for in the controller system using the quadratic calibration equation for calculating the actual flow rate from the corresponding digital signal and vice versa.

\section{Mathematical Model}

The GLC is a model-based control method; therefore, a mathematical description of the process (in state-space form) is needed to synthesize the control law. The following mathematical model is developed based on mass and energy balances.

\section{Rate laws}

Considering the standard free radical polymerization kinetic mechanism (Ray, 1972; Baillagou and Soong, 1985b; Tirrell et al., 1987) shown in Table 2 and the standard assumptions,

- Quasi-steady-state approximation (QSSA) and long-chain hypothesis (LCH)

- All the reaction steps are elementary and irreversible

- The rates of the reaction steps are independent of the live polymer chain length

- The rate of chain transfer to solvent reactions are negligible compared to the other reactions,

the consumption rates of the reactants (Ray, 1972; Baillagou and Soong, 1985b) are given by:

$$
\begin{aligned}
R_{m} & =-C_{m} \xi_{0}\left(k_{P}+k_{f_{m}}\right), \\
R_{i} & =-k_{i} C_{i},
\end{aligned}
$$

where $C_{m}, C_{i}$ and $\xi_{0}$ are the molar concentrations of the monomer, initiator and live polymer chains, respectively. $\xi_{0}$ is given by:

$$
\xi_{0}=\left(\frac{2 f k_{i} C_{i}}{k_{t}}\right)^{0.9}
$$

where $f$ is the initiator efficiency.

Free radical chain polymerizations are characterized by the presence of auto-acceleration (gel effect) in the polymerization rate as the reaction proceeds. To introduce the gel and glass propagation effects in the model, the gel and glass effect models originally developed by Chiu et al, (1983) are used. The models have the following forms (here for ease of notation, the parameters $k_{\theta_{r}}$ and $k_{\theta_{p}}$ are replaced by their inverses):

$$
\begin{aligned}
& k_{t}=\frac{k_{t_{0}}}{1+\frac{\xi_{0} k_{t_{0}}}{D k_{\theta_{t}}}}, \\
& k_{P}=\frac{k_{P_{0}}}{1+\frac{\xi_{0} k_{P_{0}}}{D k_{\theta_{p}}}},
\end{aligned}
$$

where

$$
D=\exp \left(\frac{2.3\left(1-\phi_{p}\right)}{A(T)+B\left(1-\phi_{p}\right)}\right)
$$

$\phi_{p}$ is the volume fraction of the polymer in the reactor and is defined by:

$$
\phi_{p}=\frac{\frac{\mu_{1}}{\rho_{p}}}{\frac{\mu_{1}}{\rho_{p}}+\frac{C_{m} M_{m}}{\rho_{m}}+\frac{C_{s} M_{s}}{\rho_{s}}},
$$

where $\mu_{1}$ is the mass concentration of the dead polymer chains, and $k_{t_{0}}$ and $k_{P_{0}}$ are the overall termination and propagation rate constants at zero conversion. Chiu et al. (1983) in the model development did not make the QSSA for the live polymer chains and calculated the value of $\xi_{0}$ by integrating a differential equation for $\dot{\xi}_{0}$. Here, by making the QSSA without significant loss of accuracy of the model, the differential equation $\dot{\xi}_{0}$ of Chiu et al. was changed to the algebraic equation of Eq. 2. As a result of the above gel-effect model, Eq. 2 takes the form:

$$
\xi_{0}=\left[\frac{2 f k_{i} C_{i}}{k_{t}\left(\xi_{0}, C_{m}, T\right)}\right]^{0.5},
$$

which is implicit in $\xi_{0}$. The solution for $\xi_{0}$ is calculated numerically by iteration. Table 3 shows the definitions and values of the parameters of the gel and glass effect models for the polymerization system MMA-AIBN-toluene.

The increase in density in converting from monomer to polymer (volume contraction with conversion) is substantial (more than $22 \%$ for bulk polymerization of MMA) so that these changes must be considered in modeling the reactor. To include the effect of the volume shrinkage in the model, the following linear correlation (Schmidt and Ray, 1981; Hamer et al., 1981; Baillagou and Soong, 1985b; Tirrell et al., 1987): 
Table 3. Definitions and Values of the Gel and Glass Effect Model Parameters (Baillagou and Soong, 1985b)

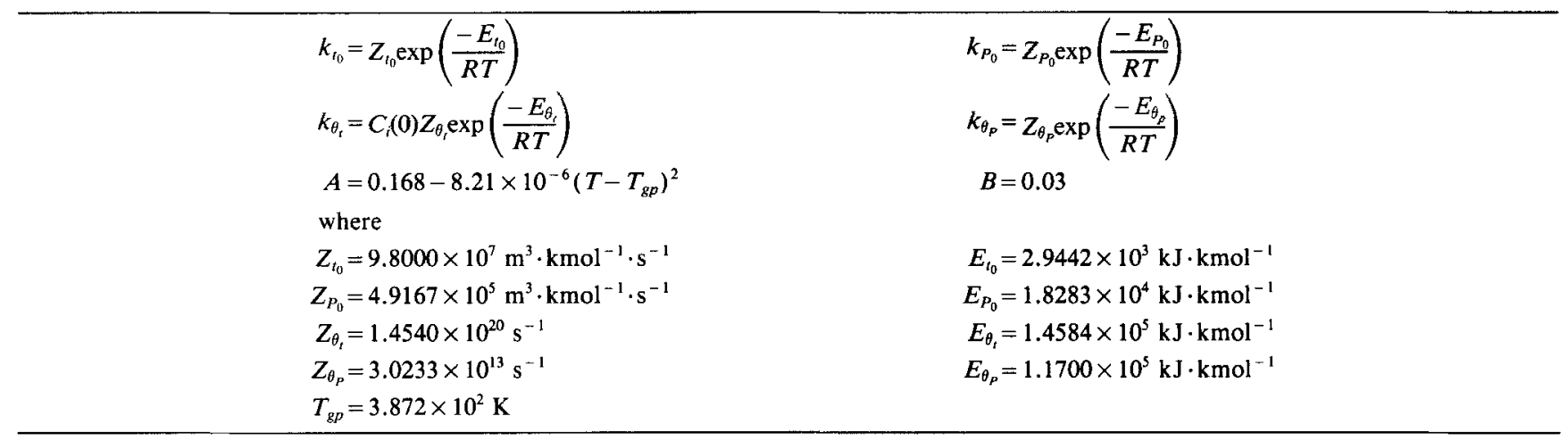

$$
V=V_{0}\left(1+\epsilon X_{m}\right)
$$

is used. $\epsilon$ is the volume expansion factor and is determined by:

$$
\epsilon=\phi_{m_{0}}\left(\frac{\rho_{m}}{\rho_{p}}-1\right)
$$

where $\phi_{m_{0}}=C_{m_{0}} M_{m} / \rho_{m}$ is the volume fraction of the monomer at the start of reaction. $x_{m}$ is the fractional conversion of the monomer and is given by:

$$
x_{m}=\frac{C_{m_{0}} V_{0}-C_{m} V}{C_{m_{0}} V_{0}}=\frac{1-\frac{C_{m}}{C_{m_{0}}}}{1+\epsilon \frac{C_{m}}{C_{m_{0}}}} .
$$

The other kinetic and physical parameters for the system of MMA, AIBN and toluene are given in Table 4.

Because of the $\mathrm{LCH}$, the overall rate of heat production by the reactions is given by:

$$
R_{H}=\left(-\Delta H_{P}\right) k_{P} \xi_{0} C_{m}
$$

\section{Heat-transfer coefficient and area correlations}

During the course of polymerization, as the reactions proceed, the concentration of the polymer chains increases. This increase in the polymer concentration primarily causes the viscosity of the reacting mixture to increase significantly (in this study, the kinematic viscosity of the reacting mixture was observed to increase from almost $0.5 \mathrm{cSt}$ to more than $400 \mathrm{cSt}$ within the first three hours of the batch operation), which results in a sharp decrease of the overall heat-transfer coefficient $U$.

In the literature, the decrease of the overall heat-transfer coefficient in batch polymerization reactors has been modeled through the use of empirical correlations. For instance, Takamatsu et al. (1987) used an empirical correlation of the form:

$$
U\left(x_{m}\right)=U_{0}\left[1-a \exp \left(1-\frac{1}{x_{m}}\right)\right]
$$

where $a$ is a constant parameter and $U_{0}$ is the value of the heat-transfer coefficient at $x_{m}=0$ (when no polymer in the reactor) to account for the reduction of the overall heat-transfer coefficient in the mathematical modeling of an isothermal batch reactor. In a conceptually similar, but more rigorous, approach, Chylla and Hasse (1990) proposed an empirical exponential correlation to relate $U$ to the viscosity of the reacting mixture. They also provided a correlation to relate the mixture viscosity to the monomer conversion and temperature.

In this study, the heat-transfer coefficient $(U)$ is assumed to be a function of the monomer conversion only. In particular, the empirical correlation:

$$
U=U_{0}\left[\mathfrak{Q}+(1-\mathfrak{Q}) \exp \left(-\mathfrak{B} x_{m}{ }^{e}\right)\right]
$$

is assumed to hold. The parameters $\mathscr{Q}, \mathbb{B}$ and $\mathcal{C}$ are given in Table 4 . The correlation of Eq. 4 represents an exponential

Table 4. Other Physical and Kinetic Parameters (Baillagou and Soong, 1985b)

$$
\begin{aligned}
k_{f_{m}} & =Z_{f_{m}} \exp \left(\frac{-E_{f_{m}}}{R T}\right) \\
R & =8.345 \times 10^{0} \mathrm{~kJ} \cdot \mathrm{kmol}^{-1} \cdot \mathrm{K}^{-1} \\
Z_{f_{m}} & =4.6610 \times 10^{9} \mathrm{~m}^{3} \cdot \mathrm{kmol}^{-1} \cdot \mathrm{s}^{-1} \\
Z_{i} & =1.0533 \times 10^{15} \mathrm{~s}-1 \\
M_{i} & =1.6421 \times 10^{2} \mathrm{~kg} \cdot \mathrm{kmol}^{-1} \\
c & =2.20 \times 10^{0} \mathrm{~kJ} \cdot \mathrm{kg}{ }^{-1} \cdot \mathrm{K}^{-1} \\
m & =1.257 \times 10^{0} \mathrm{~kg} \\
\rho_{s} & =8.420 \times 10^{2} \mathrm{~kg} \cdot \mathrm{m}^{-3} \\
M_{m} & =1.0012 \times 10^{2} \mathrm{~kg} \cdot \mathrm{kmol}^{-1} \\
Q & =2.0 \times 10^{-1} \\
\mathrm{C} & =3.0 \times 10^{0}
\end{aligned}
$$


decrease in the overall heat-transfer coefficient as the conversion increases (see, Soroush, 1992, for the details).

Furthermore, as a result of the decrease in the volume of the reacting mixture, the effective heat-transfer area $(A)$ decreases as the polymerization reactions proceed. The reduction in the volume of the reacting mixture was modeled by the correlation of Eq. 3. Considering this correlation and the cylindrical shape of the reactor, we obtain the linear correlation:

$$
A\left(x_{m}\right)=A_{0}\left(1+\epsilon X_{m}\right)
$$

where $A_{0}$ is the heat-transfer area at $x_{m}=0$, for the effective heat-transfer area $A$.

\section{Reactor dynamics}

Species balances for the monomer, initiator, solvent and dead polymer and an energy balance for the reactor (assuming constant reacting mixture heat capacity $c$ and perfect mixing) give the set of ordinary differential equations:

$$
\left\{\begin{array}{l}
\frac{d C_{m}}{d t}=\left(1+\epsilon \frac{C_{m}}{C_{m_{0}}}\right) R_{m}, \\
\frac{d C_{i}}{d t}=R_{i}+\epsilon \frac{C_{i}}{C_{m_{0}}} R_{m}, \\
\frac{d T}{d t}=\frac{\alpha_{0} k_{P} \xi_{0} C_{m}}{1+\epsilon \frac{C_{m}}{C_{m_{0}}}}+\alpha_{1}\left(x_{m}\right)\left(T_{j}-T\right)
\end{array}\right.
$$

where

$$
\begin{gathered}
\alpha_{0}=\frac{\left(-\Delta H_{P}\right) V_{0}(1+\epsilon)}{m c}, \quad \alpha_{1}\left(x_{m}\right)=\frac{A\left(x_{m}\right) U\left(x_{m}\right)}{m c}, \\
C_{s}=C_{s_{0}}\left(\frac{1+\epsilon \frac{C_{m}}{C_{m_{0}}}}{1+\epsilon}\right), \\
\mu_{1}=\frac{M_{m}}{1+\epsilon}\left(C_{m_{0}}-C_{m}\right) .
\end{gathered}
$$

\section{Jacket dynamics}

Under the assumptions of uniform temperature of the jacket fluid inside the circulation tubes (because of the high capacity of the circulating pump, the difference between the measured inlet and outlet jacket temperatures is negligible), and constant heat capacity of water $c_{w}$, an energy balance for the jacket gives:

$$
\begin{aligned}
\frac{d T_{j}}{d t}=\alpha_{2}\left(x_{m}\right)\left(T-T_{j}\right)+\alpha_{3}( & \left.T_{\infty}-T_{j}\right) \\
& +\alpha_{4}\left[\boldsymbol{P}-F_{c w} \rho_{w} c_{w}\left(T_{j}-T_{c w}\right)\right],
\end{aligned}
$$

where

$$
\alpha_{2}\left(x_{m}\right)=\frac{U\left(x_{m}\right) A\left(x_{m}\right)}{c_{w} m_{o}}, \quad \alpha_{3}=\frac{U_{\infty} A_{\infty}}{c_{w} m_{o}}, \quad \alpha_{4}=\frac{1}{c_{w} m_{o}} .
$$

Therefore, the dynamics of the reactor and jacket is governed by:

$$
\left\{\begin{aligned}
\frac{d C_{m}}{d t}= & \left(1+\epsilon \frac{C_{m}}{C_{m_{0}}}\right) R_{m}, \\
\frac{d C_{i}}{d t}= & R_{i}+\epsilon \frac{C_{i}}{C_{m_{0}}} R_{m}, \\
\frac{d T}{d t}= & \frac{\alpha_{0} k_{p} \xi_{0} C_{m}}{C_{m}}+\alpha_{1}\left(x_{m}\right)\left(T_{j}-T\right) \\
& 1+\epsilon \frac{d T_{j}}{C_{m_{0}}}= \\
& \alpha_{2}\left(x_{m}\right)\left(T-T_{j}\right)+\alpha_{3}\left(T_{\infty}-T_{j}\right) \\
& +\alpha_{4}\left[P-F_{c w} \rho_{w} c_{w}\left(T_{j}-T_{c w}\right)\right]
\end{aligned}\right.
$$

In a compact form, $\alpha_{1}\left(x_{m}\right)$ and $\alpha_{2}\left(x_{m}\right)$ are given by [as a result of Eqs. 4 and 5 and the definitions of the parameters $\alpha_{1}\left(x_{m}\right)$ and $\alpha_{2}\left(x_{m}\right)$ ]:

$$
\alpha_{1}\left(x_{m}\right)=\alpha_{1_{0}}\left(1+\epsilon X_{m}\right)\left[\mathscr{Q}+(1-\mathcal{Q}) \exp \left(-\Theta x_{m}{ }^{e}\right)\right]
$$

and

$$
\alpha_{2}\left(x_{m}\right)=\alpha_{2_{0}}\left(1+\epsilon X_{m}\right)\left[\mathscr{Q}+(1-\mathfrak{Q}) \exp \left(-\mathscr{B} x_{m}{ }^{e}\right)\right]
$$

where $\alpha_{1_{0}}$ and $\alpha_{2_{0}}$ are the values of $\alpha_{1}$ and $\alpha_{2}$ at $x_{m}=0$.

\section{Optimal Loading and Operating Conditions}

Using standard techniques from optimal control theory, one can compute the optimal loading conditions and reactor temperature profile under which the reactor should produce a polymer product with the following specifications:

- Its molecular weight distribution (MWD) is as narrow as possible (minimum polydispersity index, $\mathrm{PDI}$ ).

- Its weight-average molecular weight $\left(M_{w}\right)$ is $4.0 \times 10^{5}$

for a monomer conversion of at least 0.975 , batch time of 6 hours and initial solvent volume fraction of 0.30 (see Soroush and Kravaris, 1992a, for the details).

In a mathematical context, the optimization problem is to find the optimal initial monomer and initiator concentrations and the optimal reactor temperature profile which minimize the polydispersity index of the MWD subject to the terminal constraints on the weight-average molecular weight and monomer conversion.

Figure 2 depicts the computed optimal temperature profile $T^{*}(t)$ (Soroush and Kravaris, 1992a). The corresponding computed optimal loading conditions are $C_{i}^{*}(0)=0.13 \mathrm{kmol} \cdot \mathrm{m}^{-3}$ and $C_{m}^{*}(0)=6.01 \mathrm{kmol} \cdot \mathrm{m}^{-3}$. The operation of the polymerization reactor, under the above optimal loading conditions and the optimal reactor temperature profile $T^{*}(t)$ shown in Figure 2, theoretically should produce a polymer product with the specifications: $M_{w}\left(t_{f}\right)=3.95 \times 10^{5}, x_{m}\left(t_{f}\right)=0.99$ and $\operatorname{PDI}\left(t_{f}\right)=2.45$, where $t_{f}=6.0 \mathrm{~h}$.

As Figure 2 shows, the optimal temperature profile is almost constant until $t=4.5 \mathrm{~h}$, after which the temperature abruptly increases and then decreases. The start of the sharp rise in temperature is exactly at the onset of auto-acceleration (during which the rate of heat production by the reactions is maximal). Forcing the batch reactor to follow the bell-shape part of the 


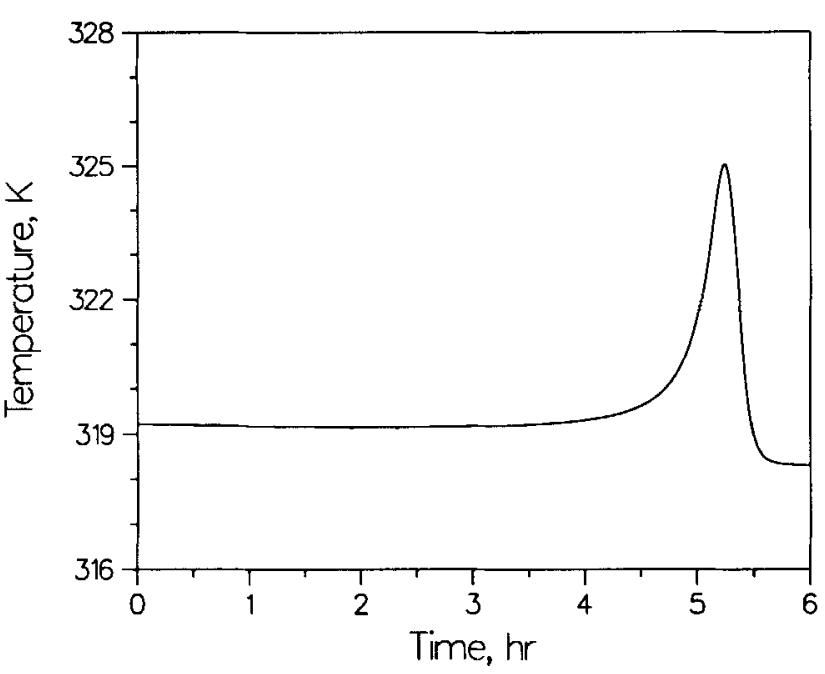

Figure 2. Optimal reactor temperature profile $T^{*}(t)$.

optimal temperature profile is challenging for the following reasons:

(i) Even under no reaction conditions (no heat production by the reactions, no decrease in the overall heat-transfer coefficient, perfect mixing), this is a difficult tracking problem because of the bell shape of the profile.

(ii) As the reactor temperature increases along the left side of the bell, the rate of the polymerization reactions increase sharply due to (a) the increase in the reactor temperature and (b) the stronger gel effect. Therefore, at the peak temperature, after which the reactor temperature should start decreasing, the rate of heat production by the reactions is maximum.

(iii) As the reactor temperature increases along the increasing part of the bell, because of the sharp increase in the rate of the polymerization reactions, viscosity of the reacting mixture rises, which results in a sharp decrease in the overall heattransfer coefficient and very poor mixing.

Therefore, to force the reactor temperature to decrease at the time when the process is at the peak temperature, a controller should act aggressively and at the same time precisely.

\section{Parameter Estimation}

In the postulated process model of Eq. 8, the four parameters $\alpha_{1_{n}}, \alpha_{2_{0}}, \alpha_{3}$, and $\alpha_{4}$ are unknown and, therefore, have to be estimated. The unknown parameters are estimated by leastsquares analysis (linear regression) from experimental data. Considering the last two equations of the dynamic model of Eq. 8, one can easily estimate these process parameters. In what follows, a brief summary of the results of the least-squares parameter estimation is provided:

- Estimation of $U_{\infty} A_{\infty}$. Under the conditions of the only solvent in the reactor, steady-state ( $T$ and $T_{j}$ constant), and no inlet cooling water $\left(F_{c w}=0\right)$, according to the model of Eq. 8 , the dependence of the difference in the jacket temperature and room temperature $\left(T_{j}-T_{\infty}\right)$ on the heater power $(P)$ is linear. In this case, the slope of the fitted regression line to the measurements of $\left(T_{j}-T_{\infty}\right)$ for different settings of $\boldsymbol{P}$ gives the least-squares estimate of $1 /\left(U_{\infty} A_{\infty}\right)=179.53 \mathrm{~s} \cdot \mathrm{K} \cdot \mathrm{kJ}^{-1}$ $\left(U_{\infty} A_{\infty}=0.00557 \mathrm{~kJ} \cdot \mathrm{s}^{-1} \cdot \mathrm{K}^{-1}\right)$.

- Estimation of $\alpha_{3}$. Under the conditions of only stagnant air in the reactor and no inlet cooling water $\left(F_{c w}=0\right)$, according to the model of Eq. 8, when there is a step change in the heater power $(P), \ln \left[\left(T_{j}-P /\left(U_{\infty} A_{\infty}\right)-T_{\infty}\right) /\left(T_{j_{0}}-P /\left(U_{\infty} A_{\infty}\right)-T_{\infty}\right)\right]$ is a linear function of time. In this case, the slope of the fitted regression line to $\ln \left[\left(T_{j}-\boldsymbol{P}\right) /\left(U_{\infty} A_{\infty}\right)-T_{\infty}\right) /\left(T_{j_{0}}-\boldsymbol{P} /\right.$ $\left.\left.\left(U_{\infty} A_{\infty}\right)-T_{\infty}\right)\right]$ data for different time instants gives the leastsquares estimate of $\alpha_{3}\left(\alpha_{3}=0.00037 \mathrm{~s}^{-1}\right)$.

- Estimation of $\alpha_{10^{-}}$In the presence of the only solvent in the reactor $\left(x_{m}=0\right)$, according to the model of Eq. 8, when there is a step change in the jacket temperature $\left(T_{j}\right)$, $\ln \left[\left(T-T_{c w}\right) /\left(T_{0}-T_{c w}\right)\right]$ is a linear function of time. The step change in the jacket temperature is achieved by switching the control valve position from fully closed to fully open under no power to the heater. In this case, the slope of the fitted regression line to $\ln \left[\left(T-T_{c w}\right) /\left(T_{0}-T_{c w}\right)\right]$ data for different time instants gives the least-squares estimate of $\alpha_{1_{0}}\left(\alpha_{1_{0}}=0.0038\right.$ $\mathrm{s}^{-1}$ ).

- Calculation of $\alpha_{4}$ and $\alpha_{20^{*}}, \alpha_{4}$ and $\alpha_{2_{0}}$ are calculated easily as follows: $\alpha_{4}=\alpha_{3} /\left(U_{\infty} A_{\infty}\right)=0.0664 \mathrm{~K} \cdot \mathrm{kJ}^{-1}, \alpha_{2_{0}}=\alpha_{1_{0}} \alpha_{4}$ $m c=0.0008 \mathrm{~s}^{-1}$.

\section{Coordination Rules}

Since it is undesirable (energywise) to have heating and cooling simultaneously, the two actual manipulated inputs ( $P$ and $F_{c w}$ ) must be coordinated by some coordination rules, which results in combining the two manipulated inputs into one. One approach is to combine the manipulated inputs linearly as suggested by Jutan and Uppal (1984). A disadvantage associated with this linear combination is that almost always both heating and cooling take place simultaneously; this is undesirable energywise. In this work, the following coordination approach is used to combine the two actual manipulated inputs $P$ and $F_{c w}$ :

- Set

$$
u=\boldsymbol{P}-F_{c w} c_{w} \rho_{w}\left(T_{j}-T_{c w}\right)
$$

which represents the net rate of heat addition to the jacket circulating system by the inlet coolant and the heater.

- Once $u$ has been calculated by a control law, $P$ and $F_{c w}$ are set according to the following coordination rules:

$$
\begin{gathered}
\boldsymbol{P}= \begin{cases}u, & \text { if } 0 \leq u<\boldsymbol{P}_{\max } \\
\boldsymbol{P}_{\max }, & \text { if } u \geq \boldsymbol{P}_{\max } \\
0, & \text { if } u<0\end{cases} \\
F_{c w}= \begin{cases}\frac{-u}{c_{w} \rho_{w}\left(T_{j}-T_{c w}\right)}, & \text { if }-F_{c w_{\max }} c_{w} \rho_{w}\left(T_{j}-T_{c w}\right) \leq u<0 \\
F_{c w_{\max },} & \text { if } u<-F_{c w_{\max }} c_{w} \rho_{w}\left(T_{j}-T_{c w}\right) \\
0, & \text { if } u \geq 0\end{cases}
\end{gathered}
$$

The dependence of $\boldsymbol{u}$ on $\boldsymbol{P}$ and $F_{c w}$ is clearly nonlinear.

The overall dynamic model of the reactor (combining Eqs. 8 and 9), in a compact form, is given by: 


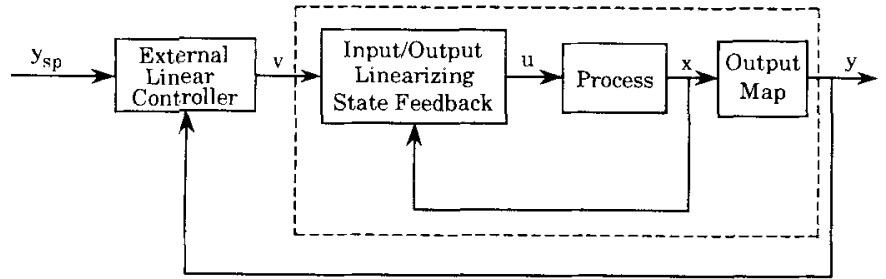

Figure 3a. GLC state- and output-feedback structure.

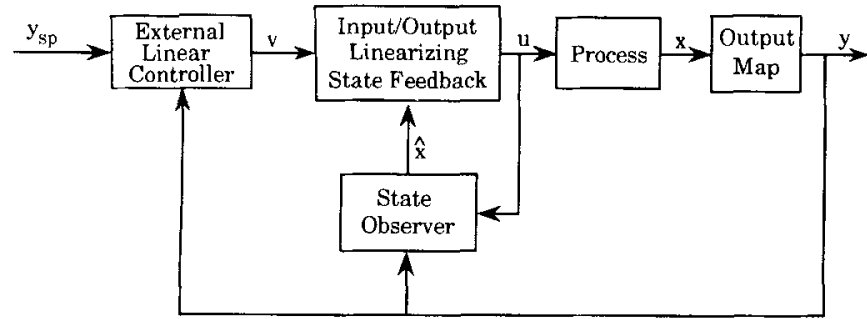

Figure 3b. GLC output-feedback structure.

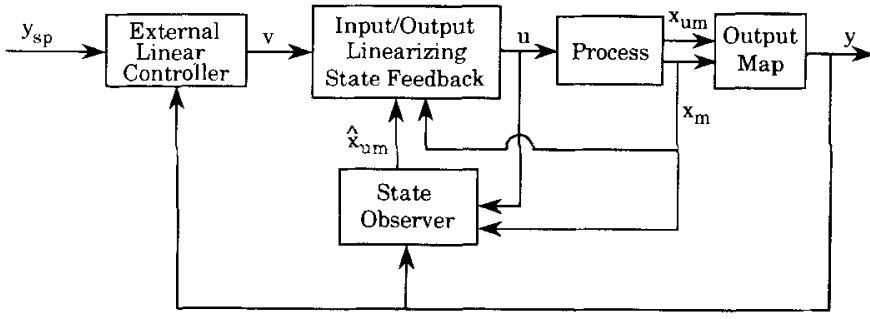

Figure 3c. GLC hybrid structure.

$$
\left\{\begin{array}{l}
\frac{d C_{m}}{d t}=f_{1}\left(C_{m}, C_{i}, T\right) \\
\frac{d C_{i}}{d t}=f_{2}\left(C_{m}, C_{i}, T\right) \\
\frac{d T}{d t}=f_{3}\left(C_{m}, C_{i}, T, T_{j}\right) \\
\frac{d T_{j}}{d t}=f_{4}\left(C_{m}, T, T_{j}\right)+\alpha_{4} u
\end{array}\right.
$$

\section{The GLC Method: a Review}

The first step in the GLC synthesis framework is the calculation of a static-state feedback, under which the closedloop input/output system is exactly linear (see Kravaris and Chung, 1987; Kravaris and Soroush, 1990 for the details). This is depicted in Figure 3a, in which the input/output behavior of the system inside the dotted line block ( $v-y$ system) is exactly linear. Once the inner loop is closed, the controller design reduces to the design of an external linear controller with integral action. This external linear controller is needed for the purpose of controller robustness and rejection of process disturbances.

To implement the state feedback of the GLC, all the process state variables should be measured or estimated on-line. Depending on the availability of state variable measurements, one of the following control structures is used:

(A) "Basic" GLC Scheme: Full State Measurement. This is the case when all the process states are measured on-line. The corresponding controller block diagram is depicted in Fig- ure 3a. The controller, in this case, is a mixed state- and outputfeedback controller.

(B) GLC-Output Feedback Scheme: Only Output Measurement. This is the case when only the process output variables are measured. In this case, a state observer should be used to estimate all the state variables. The theoretical properties of the state feedback/state observer combination have been investigated by Daoutidis and Kravaris (1992) and Daoutidis et al. (1991). The corresponding controller block diagram is depicted in Figure $3 \mathrm{~b}$.

(C) GLC-Hybrid Scheme: Partial State Measurement. This is the case when only a subset of the process state variables are measured in addition to the outputs. In this case, a state observer should be used to estimate those state variables which are not measured, leading to a control scheme which is hybrid of schemes A and B. The corresponding controller block diagram is depicted in Figure 3c. In this figure, $x_{m}$ and $x_{k m}$ denote the vector of those state variables which are and are not measured, respectively. $\hat{x}_{u m}$ represents the vector of the estimated values of the unmeasured state variables.

In this experimental study, some of the state variables (temperatures) are measured, and the remaining state variables (concentrations of the initiator and monomer) are not measured. Therefore, a control scheme of type $\mathrm{C}$ will be used.

In the GLC structure, the external controller consists of a linear controller with integral action, for example, a PI or PID controller. For control problems that involve constant set points, the bias of the external controller is normally taken to be constant. In batch processes, however, where the objective is to track an a priori known smooth time-varying set-point profile $y_{s p}(t)$, controller performance is greatly improved by using a time-varying bias for the external controller. In what follows, a brief review of the GLC synthesis approach will be provided, which will include a derivation of a time-varying bias for the external controller.

Consider SISO processes which are described by a model of the form:

$$
\left\{\begin{array}{l}
\dot{x}=f(x)+g(x) u \\
y=h(x)
\end{array}\right.
$$

with a finite relative order $r$ [the relative order $r$ is the smallest integer for which $L_{g} L_{f}^{r-1} h(x) \neq 0$ ]. Here $x \in \mathbb{R}^{n}$ is the vector of state variables, $u \in \mathbb{R}$ and $y \in \mathbb{R}$ are the manipulated input and the controlled output, respectively. Under the state feedback:

$$
u=\frac{v-h(x)-\sum_{\ell=1}^{r} \beta_{\ell} L_{f}^{\ell} h(x)}{\beta_{r} L_{g} L_{f}^{r-1} h(x)}
$$

where $\beta_{\ell}$ 's are tunable parameters, the closed-loop $v-y$ behavior of the process described by Eq. 13 is given by:

$$
y+\sum_{\ell=1}^{r} \beta_{\ell} \frac{d^{p} y}{d t^{\ell}}=v
$$

The time-varying bias naturally arises, when Eq. 14 is recast in deviation variable form: 


$$
y^{\prime}+\sum_{\ell=1}^{r} \beta_{\ell} \frac{d^{\ell} y^{\prime}}{d t^{\ell}}=v^{\prime}
$$

where

$$
\begin{aligned}
& y^{\prime} \triangleq y-y_{s p} \\
& v^{\prime} \triangleq v-\left(y_{s p}+\sum_{P=1}^{r} \beta_{\ell} \frac{d^{\ell} y_{s p}}{d t^{\ell}}\right)
\end{aligned}
$$

and an external bias-free error feedback controller is applied to the linearized $v^{\prime}-y^{\prime}$ system (Eq. 15). For example, if a conventional PI controller is employed as the external controller, we will have:

$$
v^{\prime}(t)=K_{c}\left[e(t)+\frac{1}{\tau_{i}} \int_{0}^{t} e(\tau) d \tau\right]
$$

or equivalently,

$$
\begin{aligned}
v(t)=v_{b}(t)+K_{\mathrm{c}}\left\{\left[y_{s p}(t)-y(t)\right]\right. & \\
& \left.+\frac{1}{\tau_{I}} \int_{0}^{t}\left[y_{s p}(\tau)-y(\tau)\right] d \tau\right\},
\end{aligned}
$$

where

$$
v_{b}(t)=y_{s p}(t)+\sum_{\ell=1}^{r} \beta_{\ell} \frac{d^{\ell} y_{s p}(t)}{d t^{\ell}}
$$

is exactly the controller bias.

It is important to point out that when $y_{s p}(t)$ is slowly timevarying and/or the $\beta_{i}$ 's are small (fast dynamics of the $v-y$ system), the influence of the derivative terms in the controller bias $v_{b}(t)$ may be small, in which case $y_{s p}(t)$ could be used as the controller bias.

Remark 1 . When $y_{s p}(t)$ is not available in terms of a formula but it is in form of two arrays of numbers (for example, output of a dynamic optimization program), numerical differentiation must be performed. Standard smoothing techniques must be employed to prevent numerical instabilities in the calculation of derivatives. For example, passing the setpoint profile through the differentiator-filter (lead-lag filter);

$$
\frac{s^{\ell}}{\left(\epsilon_{\phi} s+1\right)^{\ell}}
$$

where $\epsilon_{d}$ is the filter parameter $\left(0<\epsilon_{d} \ll 1\right)$, gives an approximation of the $\ell$ th derivative of the set-point profile $y_{s p}(t)$. As $\epsilon_{d} \rightarrow 0$, the output of the differentiator-filter becomes more noisy and is a more accurate representation of the th derivative. On the other hand, as $\epsilon_{d} \rightarrow 1$, the output of the differentiator-filter becomes smoother and is a less accurate representation of the $\hat{t}$ th derivative. The first few derivatives of the set-point profile $y_{s p}(t)$ usually have a strong influence on the shape of the bias $v_{b}(t)$.

\section{Tuning Guidelines}

In this section, tuning guidelines for the GLC are proposed. These guidelines are based on physical grounds and the experience attained from this experimental study and from the application of the GLC to other chemical processes through simulations.

The key ideas in this tuning procedure are:

- The inner loop is used primarily for "linearizing" a process, not for increasing the speed of the response of the closedloop $v-y$ system. Therefore, the $r$ poles of the $v-y$ system are placed at the $r$ slowest poles of the linear approximation of the open-loop process model.

- The external linear controller is used for a fast and offsetless tracking of the set-point trajectory.

- The gain and time constants of the external PI or PID controller are tuned in a standard way (Smith and Corripio, 1985; Rivera et al., 1985) for the linear $v-y$ system.

Remark 2. The experimental observations from polymerization tests showed that the tuning parameters $\beta_{i}$ 's have a strong effect on the controller robustness (that is, the slower the closed-loop $v-y$ response, the better the controller robustness).

Since the majority of control problems are of relative order one or two, the guidelines, which are proposed here, are for systems with relative order 1 or 2 . They are as follows:

\section{Relative order $r=1$}

Select $\beta_{1}$ to be of the order of the largest time constant of the process (average value over the operating range). This can be obtained from the model or alternatively one can get a rough estimate from experimental responses (for example, step responses). In this case, the external controller will be a PI controller, which is tuned in a standard way $\left(\tau_{I}=\beta_{1}\right.$, and $K_{c}$ is adjusted for satisfactory performance).

\section{Relative order $r=2$}

One can use the process model to obtain order-of-magnitude estimates of the two dominant time constants $\tau_{1}$ and $\tau_{2}$ over the operating range and select:

$$
\begin{aligned}
& \beta_{1}=\tau_{1}+\tau_{2} \\
& \beta_{2}=\tau_{1} \tau_{2}
\end{aligned}
$$

Alternatively, if the second largest time constant is much smaller than the dominant time constant, one can obtain an order-ofmagnitude estimate of the dominant time constant $\tau_{1}$ from the experimental data (for example, from step responses) and set:

$$
\begin{aligned}
& \beta_{1}=\tau_{1}+\frac{\tau_{1}}{10} \\
& \beta_{2}=\tau_{1} \frac{\tau_{1}}{10}
\end{aligned}
$$

This ad-hoc selection of the $\beta_{i}$ 's was found to be satisfactory in our experimental and simulation studies. Finally, the external PI or PID controller is tuned in a standard way for a second-order linear system. 
Remark 3. As a result of the above tuning guidelines, as the time constant of the open-loop process increases, the values of the $\beta_{i}$ 's also increase. Therefore, the effect of the derivatives of the set-point profile on the shape of the bias $v_{b}(t)$ depends directly on the time constants of the open-loop process.

\section{Synthesis of the Control Law for the Experimental System}

The control objective is to track the calculated optimal temperature profile $T^{*}(t)$ (Figure 2 ) in the presence of disturbances by manipulating the heater power $(P)$ and the cooling water flow rate $\left(F_{c w}\right)$.

The nonlinear control law is synthesized by following the steps of the GLC method:

1. The model described by Eq. 12 , in the standard statespace form of Eq. 13, becomes:

$$
\left\{\begin{array}{c}
\frac{d}{d t}\left[\begin{array}{c}
C_{m} \\
C_{i} \\
T \\
T_{j}
\end{array}\right]=\left[\begin{array}{c}
f_{1}\left(C_{m}, C_{i}, T\right) \\
f_{2}\left(C_{m}, C_{i}, T\right) \\
f_{3}\left(C_{m}, C_{i}, T, T_{j}\right) \\
f_{4}\left(C_{m}, T, T_{j}\right)
\end{array}\right]+\left[\begin{array}{c}
0 \\
0 \\
0 \\
\alpha_{4}
\end{array}\right] u \\
y=T
\end{array}\right.
$$

Here, the vector of state variables is $x=\left[C_{m} C_{i} T T_{j}\right]^{T} \in \mathbb{R}^{4}$.

II. Calculating the relative order: $r=2\left(L_{g} h=0\right.$ and $L_{g} L_{f} h=\alpha_{1} \alpha_{4} \neq 0$ ).

III. Calculating the input/output linearizing state feedback:

$$
u=\Psi(v, x)=\frac{v-\beta_{2} \sum_{i=1}^{4} \frac{\partial f_{3}(x)}{\partial x_{i}} f_{i}(x)-\beta_{1} f_{3}(x)-T}{\beta_{2} \alpha_{1}(x) \alpha_{4}}
$$

Under this state feedback, the closed-loop $v-y$ behavior is given by:

$$
\beta_{2} \frac{d^{2} y}{d t^{2}}+\beta_{1} \frac{d y}{d t}+y=v
$$

where $\beta_{2}$ and $\beta_{1}$ are tunable parameters.

IV. As an external linear controller, using a PI controller of the form of Eq. 16:

$$
\begin{aligned}
v(t)=v_{b}(t)+K_{c}\left\{\left[T^{*}(t)-T(t)\right]\right. & \\
& \left.+\frac{1}{\tau_{I}} \int_{0}^{t}\left[T^{*}(t)-T(t)\right] d t\right\}
\end{aligned}
$$

where $K_{c}$ and $\tau_{I}$ are tuning parameters and $v_{b}(t)$ is the controller bias given by:

$$
v_{b}(t)=T^{*}(t)+\beta_{1} \frac{d T^{*}(t)}{d t}+\beta_{2} \frac{d^{2} T^{*}(t)}{d t^{2}}
$$

In some of the experimental runs, we neglect the derivative terms in Eq. 22 and use $v_{b}(t)=T^{*}(t)$.

Because of the presence of active manipulated input constraints during the startup period, the integrator of Eq. 21 is

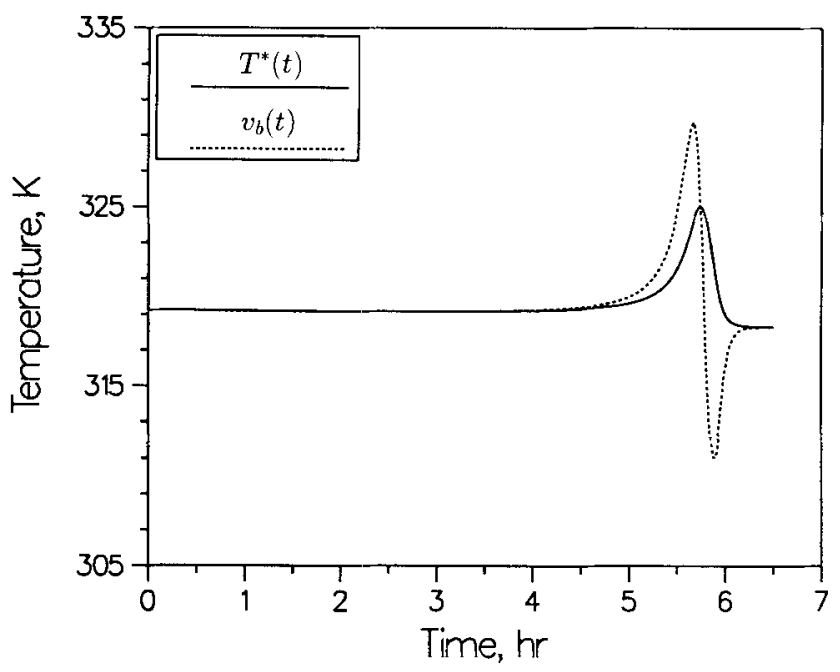

Figure 4. Set point $T^{*}(t)$ and PI-bias $v_{b}(t)$ given by Eq. 22.

"shut off" during the period of startup until $T(t)$ is close to its set-point value. This antirest windup technique is common in practice (Seborg et al., 1989).

\section{Reduced-order state observer}

In the state feedback (Eq. 20), $u$ is a function of the four states $C_{m}, C_{i}, T$, and $T_{j}$. From these four states, $C_{m}$ and $C_{i}$ are not measured on-line; therefore, they should be estimated. According to the GLC-hybrid scheme, a reduced-order observer is used to estimate the concentrations of the monomer and initiator. For the model of Eq. 12, this involves on-line integration of the first two differential equations of the model:

$$
\begin{cases}\frac{d \hat{C}_{m}}{d t}=f_{1}\left(\hat{C}_{m}, \hat{C}_{i}, T\right), & \hat{C}_{m}(0)=C_{m}(0) \\ \frac{d \hat{C}_{i}}{d t}=f_{2}\left(\hat{C}_{m}, \hat{C}_{i}, T\right), & \hat{C}_{i}(0)=C_{i}(0)\end{cases}
$$

where $\hat{C}_{m}$ and $\hat{C}_{i}$ denote the estimates of the concentrations $C_{m}$ and $C_{i}$, using the measured reactor temperature as input.

\section{Tuning parameters}

Based on the proposed tuning guidelines for $r=2, \tau_{1}$ is chosen to be $\tau_{1}=1,000 \mathrm{~s}$, which is of the same order of magnitude as the dominant process time constant (obtained from a step response of the process in the presence of the only solvent in the reactor). Therefore, the tuning parameters are: $\beta_{1}=1,100$ $\mathrm{s}, \beta_{2}=1.0 \times 10^{5} \mathrm{~s}^{2}, \tau_{I}=1,000 \mathrm{~s}$; the value of $K_{c}=10$ was found by trial and error to give satisfactory response. Note that during the batch runs no on-line tuning is attempted and the tuning parameters are fixed before the batch polymerization begins. The above values of the tuning parameters are used in all the experimental runs.

\section{Calculation of the external controller bias $v_{b}(t)$}

To calculate the PI controller bias $v_{b}(t)$ given by Eq. 22, a standard numerical differentiation procedure was followed, as given in the Appendix. Figure 4 depicts the resulting $v_{b}(t)$ profile (by using the values of $\beta_{1}$ and $\beta_{2}$ given in the previous 


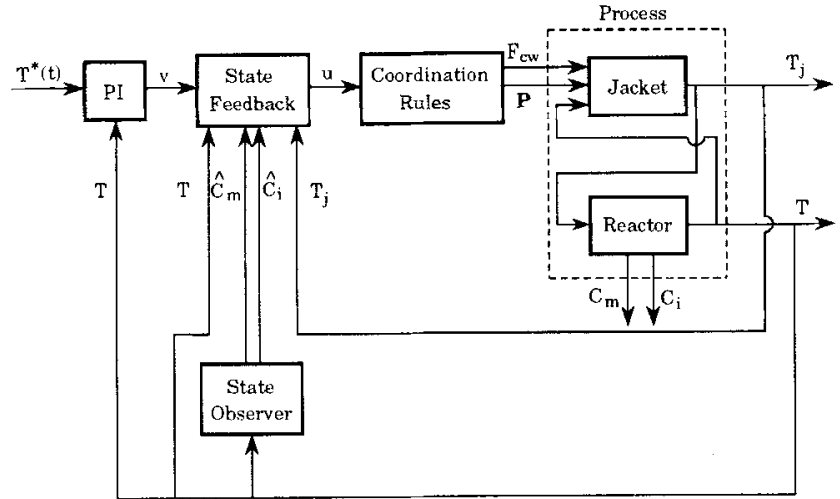

Figure 5. Controller and process.

subsection) and the optimal temperature profile $T^{*}(t)$. It is interesting to note that the bias $v_{b}(t)$ falls abruptly where the slope of the optimal profile changes sign.

For the specific values of $\beta_{1}$ and $\beta_{2}$ used in our experiment, the second derivative term $\beta_{2}\left\{\left[d^{2} T^{*}(t)\right] / d t^{2}\right\}$ had a negligible contribution on the bias $v_{b}(t)$. The first derivative term, $\beta_{1}\left\{\left[d T^{*}(t)\right\} / d t\right\}$ had a significant contribution. However, as will be seen from the experimental runs, omitting this term and using $v_{b}(t)=T^{*}(t)$ did not have a critical effect on controller performance.

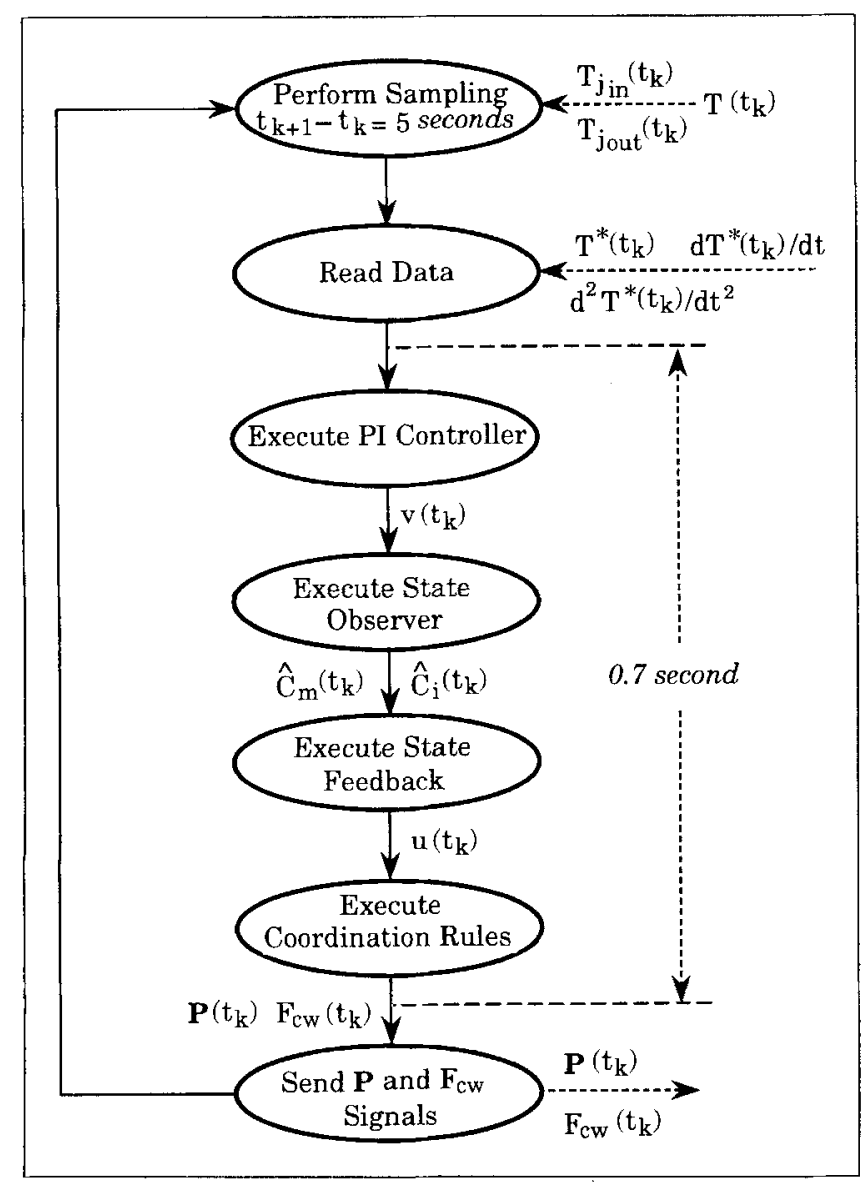

Figure 6. Flow diagram of computer program.

\section{Implementation of the Control Law}

The following discrete-time version of the nonlinear controller is used in the computer code:

$$
u\left(t_{k}\right)=\Psi\left\{v\left(t_{k}\right),\left[\hat{C}_{m}\left(t_{k}\right) \hat{C}_{i}\left(t_{k}\right) \quad T\left(t_{k}\right) T_{j}\left(t_{k}\right)\right]^{T}\right\}
$$

where $\Psi$ is defined by $\mathbf{E q . ~} 20$, and $v\left(t_{k}\right)$ is calculated from:

$$
\begin{gathered}
v\left(t_{k}\right)=v_{b}\left(t_{k}\right)+v^{\prime \prime}\left(t_{k}\right) \\
v^{\prime \prime}\left(t_{k}\right)=v^{\prime \prime}\left(t_{k-1}\right)+K_{c}\left\{\left(\frac{\Delta t}{\tau_{l}}+1\right)\left[T^{*}\left(t_{k}\right)-T\left(t_{k}\right)\right]\right. \\
\left.\left.-T^{*}\left(t_{k-1}\right)-T\left(t_{k-1}\right)\right]\right\}
\end{gathered}
$$

where $\Delta t$ is the sampling period. Equation 26 is the velocity form of a digital PI controller. $\hat{C}_{m}\left(t_{k}\right)$ and $\hat{C}_{i}\left(t_{k}\right)$ are calculated from numerical integration of the differential equations in $\mathrm{Eq}$. 23 using the 4th-order Runge-Kutta-Gill method.

Note that once the manipulated input $u\left(t_{k}\right)$ is calculated from Eq. 24, the corresponding values of the actual manipulated inputs $\boldsymbol{P}\left(t_{k}\right)$ and $F_{c w}\left(t_{k}\right)$ are calculated by using the coordination rules (Eqs. 10 and 11), which indeed impose the manipulated input constraints on the controller action. Furthermore, the integral action of the PI controller is "shut off" by setting $\tau_{I}=\infty$ (because of the use of velocity form PI controller) when an input constraint is active.

A block diagram of the process and controller is shown in Figure 5. In particular, this figure depicts the different blocks of the controller and process and their interconnections. The computer code of the controller includes the following steps in the order of their execution:

1. Executing the sampling task at time $t_{k}$ (sampling period $\Delta t=5 \mathrm{~s})$. The jacket temperature $T_{j}\left(t_{k}\right)$ is the arithmetic mean of the measurements $T_{j_{\text {in }}}\left(t_{k}\right)$ and $T_{j_{\mathrm{out}}}\left(t_{k}\right)$.

2. Reading the optimal reactor temperature $T^{*}\left(t_{k}\right)$ and its derivatives $\left[d T^{*}\left(t_{k}\right)\right] / d t$ and $\left[d^{2} T^{*}\left(t_{k}\right)\right] / d t^{2}$ from the hard disk and calculating the bias $v_{b}\left(t_{k}\right)$.

3. Executing the PI controller [calculating $v\left(t_{k}\right)$ by using Eqs. 25 and 26].

4. Executing the state observer (one-step-forward integration of Eq. 23 using the 4th-order Runge-Kutta-Gill method [integration step size $=$ sampling period], with the initial conditions $\hat{C}_{m}\left(t_{k-1}\right)$ and $\hat{C}_{i}\left(t_{k-1}\right)$ and input $T\left(t_{k}\right)$, to obtain $\hat{C}_{m}\left(t_{k}\right)$ and $\hat{C}_{i}\left(t_{k}\right)$.

5. Executing the state feedback [calculating $u\left(t_{k}\right)$ by using Eq. 24].

6. Executing the coordination rules [calculating $\boldsymbol{P}\left(t_{k}\right)$ and $F_{c w}\left(t_{k}\right)$ from Eqs. 10 and 11$]$.

7. Sending $\boldsymbol{P}\left(t_{k}\right)$ and $F_{c w}\left(t_{k}\right)$ signals to the heater and the control valve.

8. Returning to 1 .

These tasks are shown in Figure 6. By using the specific microcomputer, which is as fast as an IBM AT, the actual time (CPU time) needed for the execution of the tasks (PI controller, state observer, state feedback and coordination rules) is $0.7 \mathrm{~s}$, which is significantly less than the sampling period $(\Delta t=5 \mathrm{~s})$. This low value of CPU time on the specific microcomputer 
Table 5. List of Experimental Cases

\begin{tabular}{ccccccc}
\hline Case & Controller & PI-Bias & $U \& A$ & Inhibitor & Loading Error & Disturbance \\
\hline I & GLC & $v_{b}(t)$, Eq. 22 & $U\left(x_{m}\right) \& A\left(x_{m}\right)$ & No & No & No \\
II & GLC & $v_{b}(t)$, Eq. 22 & $U_{0} \& A_{0}$ & No & No & No \\
III & GLC & $T^{*}(t)$ & $U\left(x_{m}\right) \& A\left(x_{m}\right)$ & No & No & No \\
IV & GLC & $T^{*}(t)$ & $U_{0} \& A_{0}$ & No & No & No \\
V & GLC & $T^{*}(t)$ & $U_{0} \& A_{0}$ & Yes & No & No \\
VI & GLC & $T^{*}(t)$ & $U_{0} \& A_{0}$ & No & Yes & Yes \\
VII & GLC & $T^{*}(t)$ & $U_{0} \& A_{0}$ & No & No & No \\
VIII & GLC & $T_{s p}(t)$ & $U_{0} \& A_{0}$ & No & No & No \\
IX & PID & - & - &
\end{tabular}

shows the computational efficiency of the nonlinear control method. This becomes more significant when one considers

- The complexity of the polymerization model

- The fact that the nonlinear controller is indeed a nonlinear model predictive controller (Soroush and Kravaris, 1992b).

\section{Experimental Procedure}

Toluene is HPLC grade from Aldrich. AIBN is from Eastman Kodak. The methylmethacrylate from Aldrich contains 10-ppm hydroquinone monomethyl ether inhibitor to prevent polymerization during storage. The inhibitor is removed by passing the MMA through an ion exchange resin (from Aldrich); then the monomer is further purified by vacuum distillation at 60 torr and $34-36^{\circ} \mathrm{C}$ or 100 torr and $44-46^{\circ} \mathrm{C}$. Polymerization is performed after purging the monomer and solvent from oxygen (a reaction inhibitor) by bubbling nitrogen through them for one hour. The nitrogen bubbling is also continued during the polymerization. The reacting mixture is mixed by the multipaddle stirrer at $250 \mathrm{rpm}$.

To have a highly nonlinear process and at the same time a feasible batch operation (in terms of being able to handle mixing of the extremely viscous solution) for the batch time of $6.0 \mathrm{~h}$, a solvent fraction of 0.3 (by volume) is used in all the experimental runs. The use of this low solvent fraction gives rise to a significant gel effect during the batch operation.

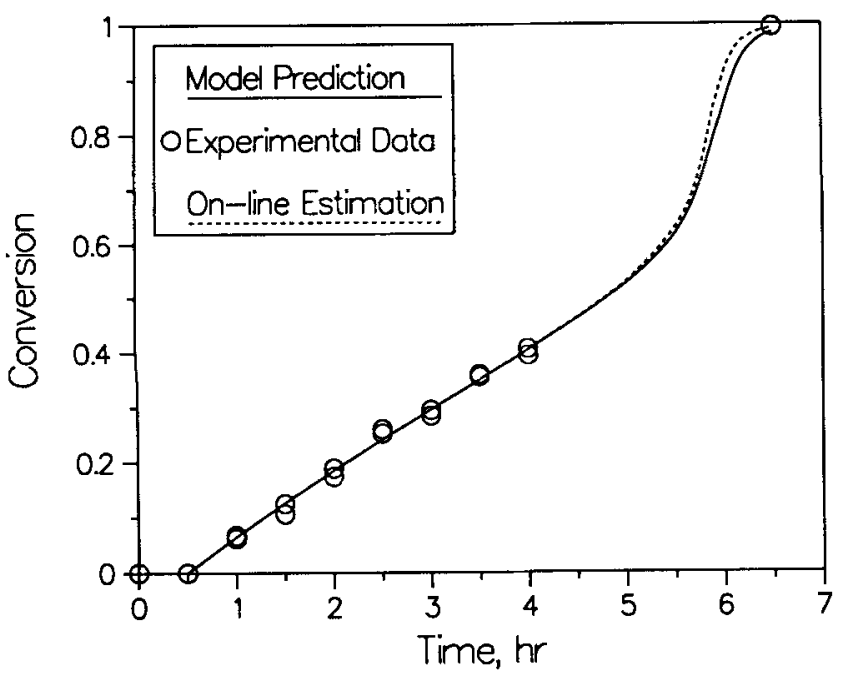

Figure 7. Comparison of model calculations and experimental data for monomer conversion.
Also because of the low solvent fraction, toward the end of a batch cycle, there are uncertain factors like solid polymer layers (formation of two phases), which cause imperfect mixing and sometimes stop the stirrer. The formation of polymer layers may make further continuation of the batch operation infeasible. The major difficulty in this study is handling the extreme viscosity and solid formation toward the end of the batch.

For each batch cycle, initially, the reactor is loaded with the optimal amounts of the monomer and solvent $(0.903 \mathrm{~kg}$ MMA and $4.50 \times 10^{-4} \mathrm{~m}^{3}$ toluene). Then, oxygen is purged from the monomer solution by bubbling nitrogen for one hour. Next the reactor is heated up from the room temperature to the optimal initial temperature $(319.2 \mathrm{~K})$ under the GLC [under no reaction conditions: $C_{i}(0)=0$ and $C_{m}(0)=6.01 \mathrm{kmol} \cdot \mathrm{m}^{-3}$ ]. At $t=0.5 \mathrm{~h}, 32.01 \mathrm{~g}$ AIBN is added to the reactor. At this moment, the reduced-order observer is initialized at $C_{i}(0.5)=0.13 \mathrm{kmol} \cdot \mathrm{m}^{-3}$ and $C_{m}(0.5)=6.01 \mathrm{kmol} \cdot \mathrm{m}^{-3}$. In intervals of $0.5-\mathrm{h} 5-\mathrm{ml}$ samples are taken from the septum located at the top of the reactor by using a syringe for the off-line analysis.

\section{Kinetic model validation}

By use of a gravimetric method (Collins et al., 1973), the amount of monomer conversion in each sample is determined. The results of the gravimetric method for cases II and III (see Table 5) and the model calculations are shown in Figure 7. In this figure, the solid line represents the calculated values of the conversion by the model under the assumption of perfect set-point tracking $\left[T(t)=T^{*}(t)\right]$. The dotted line represents the on-line model calculations of conversion using the actual reactor temperature shown in Figure 10a. Because of the extremely high viscosity of the reacting mixture for $t>4.0 \mathrm{~h}$, no more samples could be taken during this period. As depicted in Figure 7 , the experimental data agree very well with the conversions calculated by the model.

\section{Controller Performance}

In this section, the servo and regulatory performance of the controller are investigated. In particular, the following experimental runs are performed as outlined in Table 5.

\section{Case I: nominal case}

Figure 8a depicts the set-point and reactor temperature profiles for this case. As this figure shows, the reactor is initially (at $t=0$ ) at room temperature. Under the nonlinear controller, 


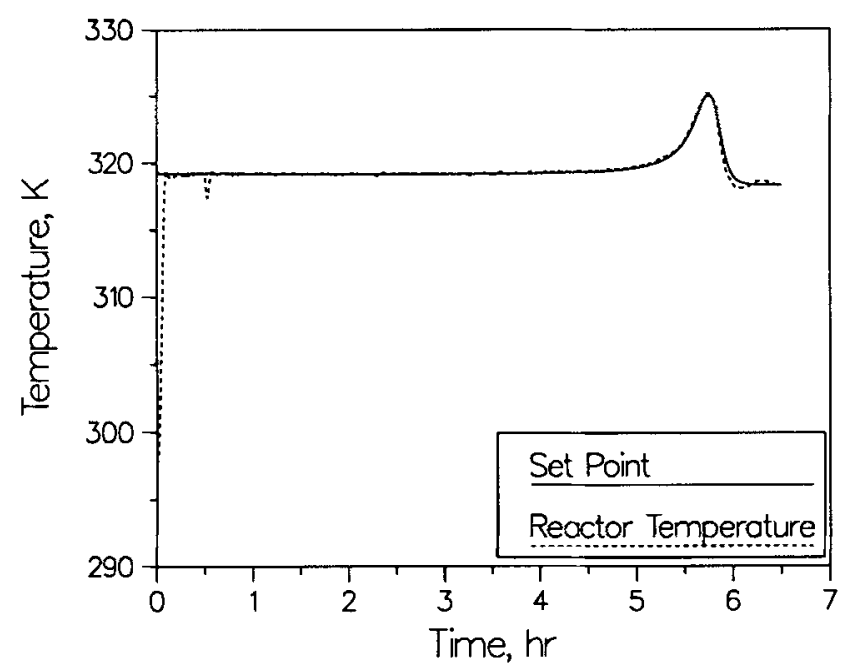

Figure 8a. Profiles of the set point and reactor temperature (case I).

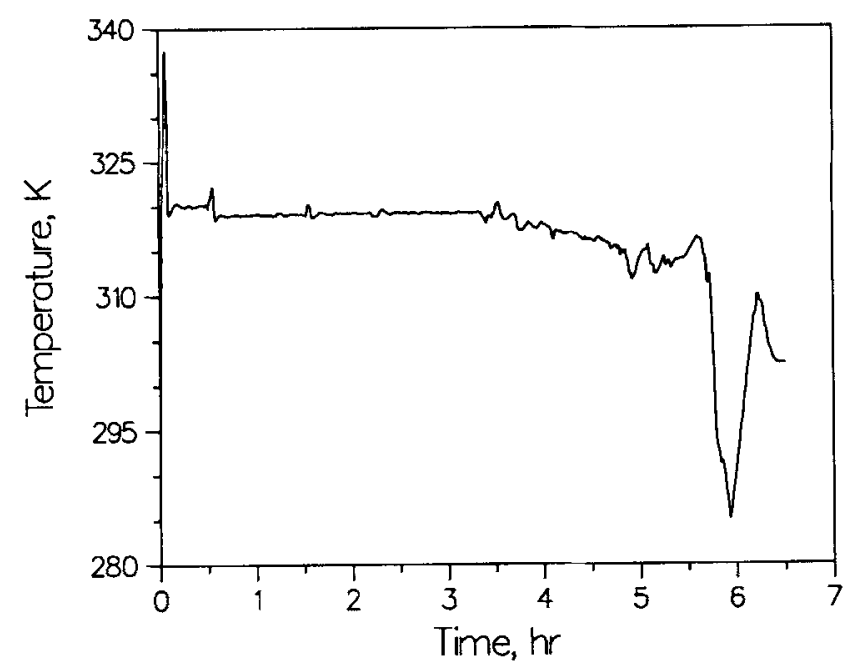

Figure $8 b$. Jacket temperature profile corresponding to Figure 8a.

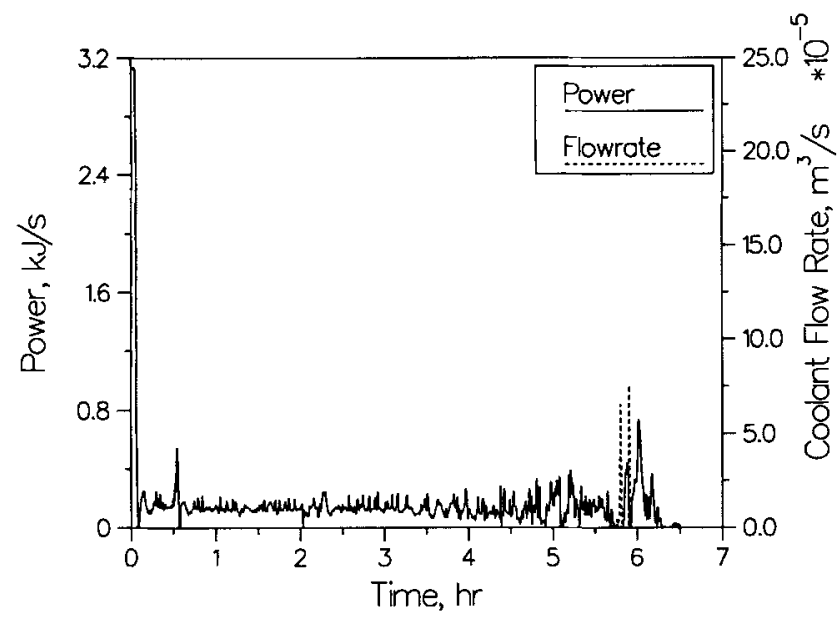

Figure 8c. Profiles of the cooling water flow rate and heater power corresponding to Figure 8 a.

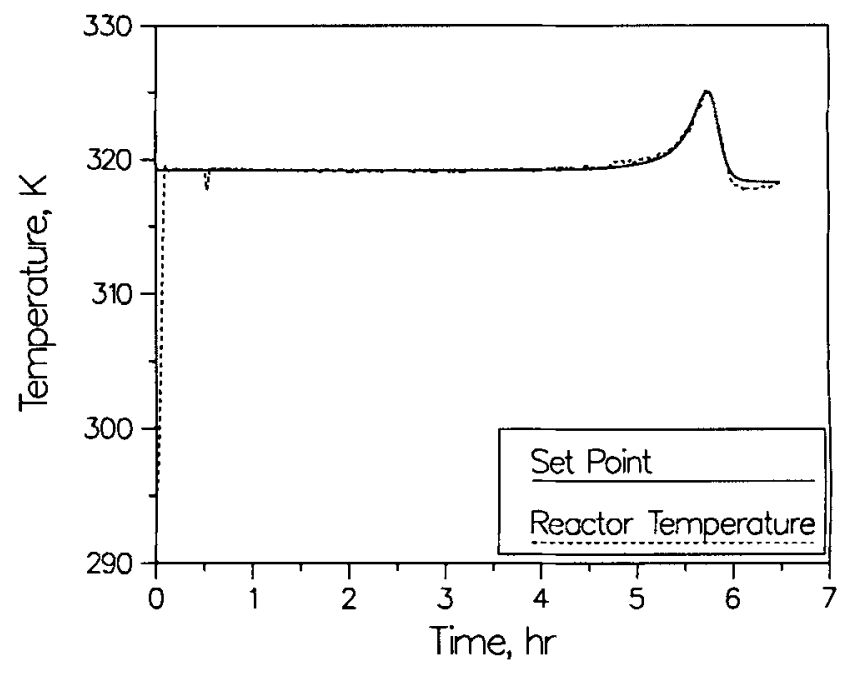

Figure 9a. Profiles of the set point and reactor temperature (case II).

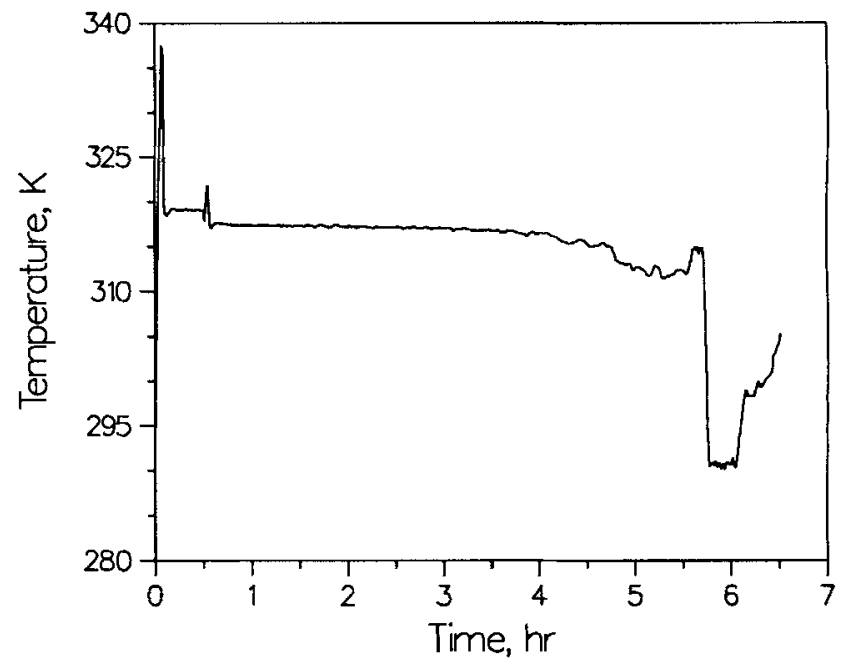

Figure $9 b$. Jacket temperature profile corresponding to Figure 9a.

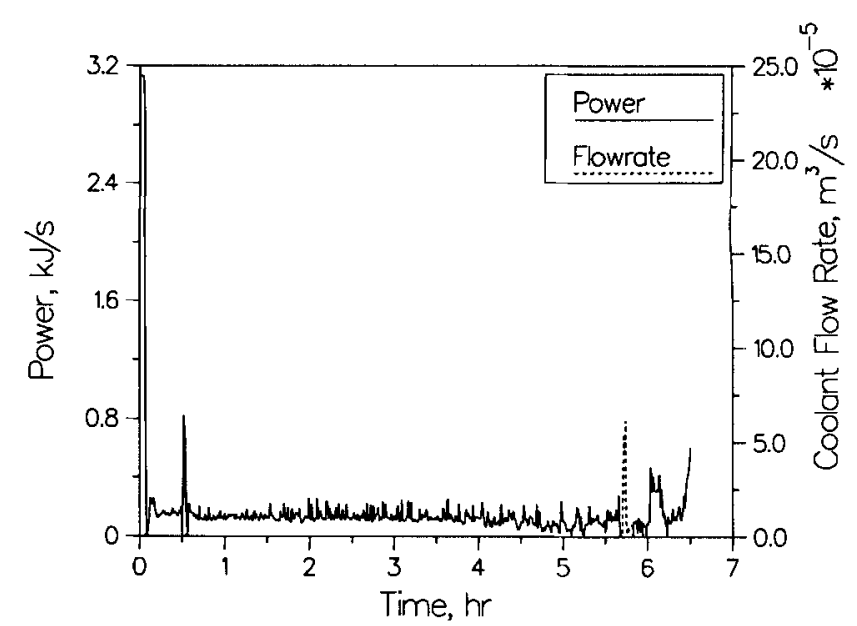

Figure 9c. Profiles of the cooling water flow rate and heater power corresponding to Figure 9a. 


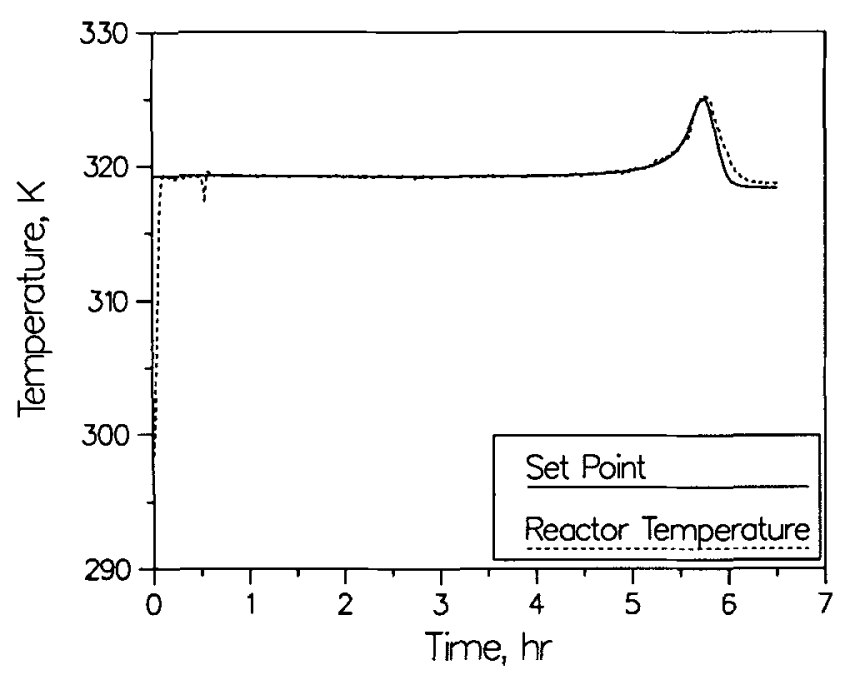

Figure 10a. Profiles of the set point and reactor temperature (case III).

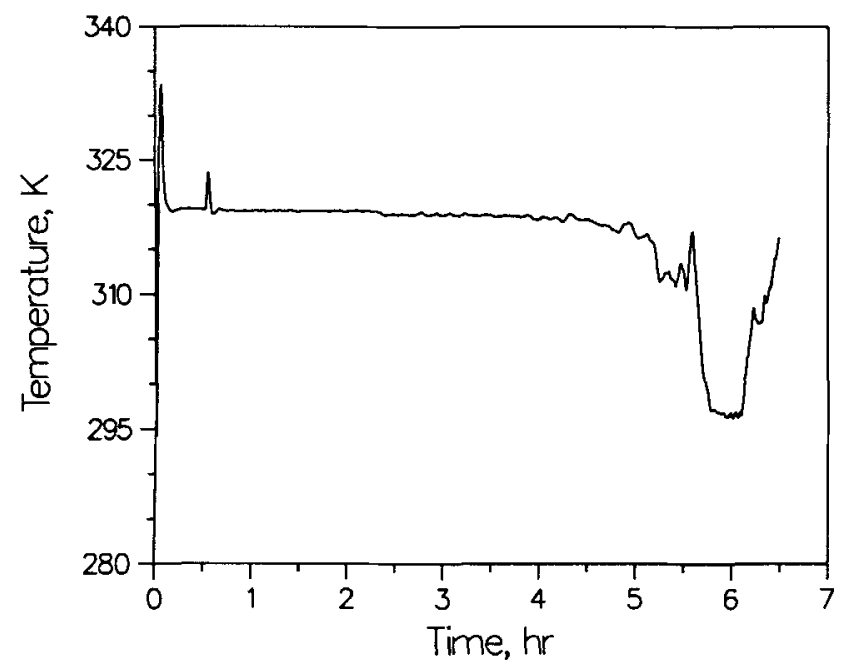

Figure 10b. Jacket temperature profile corresponding to Figure 10a.

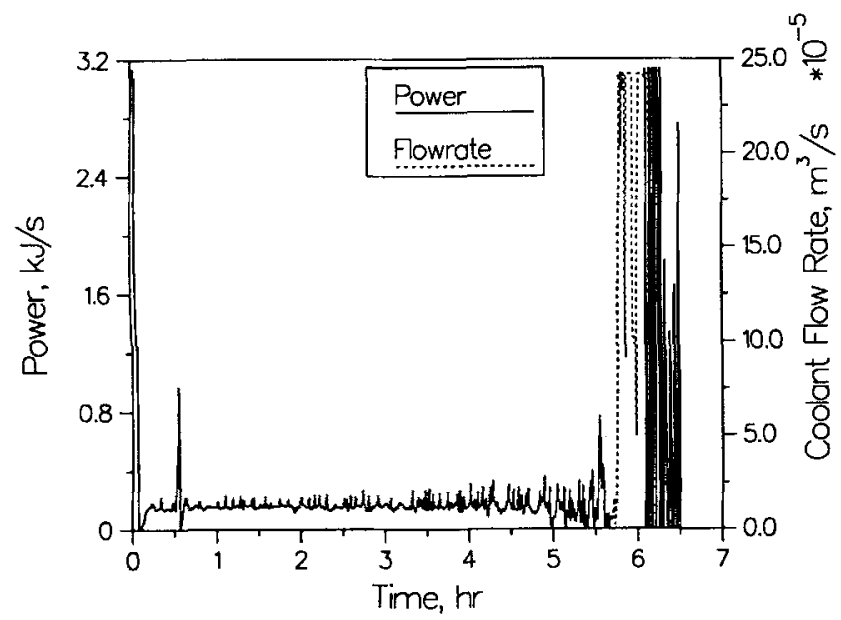

Figure 10c. Profiles of the cooling water flow rate and heater power corresponding to Figure 10a. the reactor temperature is brought to the set point without overshoot. At $t=0.5 \mathrm{~h}$, when the cold initiator is added to the reactor, the reactor temperature decreases temporarily but the controller returns the reactor temperature to its set point very fast without overshoot. During the last two hours of the operation, there are solid layers of polymer in the reactor, which causes imperfect mixing. Despite the viscosity involved, the results show excellent tracking performance of the controller. Figures $8 \mathrm{~b}$ and $8 \mathrm{c}$ depict the corresponding jacket temperature and the actual manipulated variable profiles for this case.

\section{Case II: $U=U_{0}$ and $A=A_{0}$}

In this case, the nonlinear controller is calculated based on the process model in which the heat-transfer coefficient and area ( $U$ and $A$ ) are assumed to be constant and equal to the values of $U$ and $A$ under zero monomer conversion ( $U=U_{0}$ and $A=A_{0}$ ). This case is performed to investigate the performance of the controller when a significantly less accurate model is used in the control law. Experimental results for this case are shown in Figures $9 \mathrm{a}, 9 \mathrm{~b}$ and $9 \mathrm{c}$. The performance of the controller is not as good as in case I, but it is very satisfactory. Figures $9 \mathrm{~b}$ and $9 \mathrm{c}$ depict the corresponding jacket temperature and the actual manipulated variable profiles. As can be seen from Figure 9c, the controller is relatively less aggressive toward the end of batch compared to case $I$.

\section{Case III: PI-bias $=T^{*}(t)$}

In this case, the optimal temperature profile $T^{*}(t)$ is used as PI-bias instead of $v_{b}(t)$ given by Eq. 22. Figure 10a depicts the reactor temperature for this case. This figure shows the same performance of the controller as in cases I and II, except toward the end of the batch cycle, during which the controller cannot cool the reactor as requested by the optimal profile. Figures $10 \mathrm{~b}$ and $10 \mathrm{c}$ depict the corresponding jacket temperature and the actual manipulated variable profiles. As depicted in Figure 10c, the manipulated inputs oscillated very wildly toward the end of the batch in an attempt to return the reactor temperature to its set-point value.

\section{Case IV: PI-bias $=T^{*}(t), U=U_{0}$ and $A=A_{0}$}

In this case, the optimal temperature profile $T^{*}(t)$ is used as PI-bias, instead of $v_{b}(t)$ given by Eq. 22, and the nonlinear controller is calculated based on the process model in which the heat-transfer coefficient and area $(U$ and $A)$ are assumed to be constant: $U=U_{0}$ and $A=A_{0}$. This case is also performed to illustrate the performance of controller when a significantly less accurate model is used in the control law. Experimental results for this case are shown in Figures $11 \mathrm{a}, 11 \mathrm{~b}$ and $11 \mathrm{c}$. The performance of the controller is not as good as in cases I, II and III, but it is quite satisfactory. Figures $11 \mathrm{~b}$ and $11 \mathrm{c}$ depict the corresponding jacket temperature and the actual manipulated variable profiles. As can be seen from Figure 11c, the controller is less aggressive toward the end of the batch compared to case III.

Case V: PI-bias $=T^{*}(t), U=U_{0}, A=A_{0}$, and 50\% error in initiator loading

This case is similar to case IV, but at $t=0.5 \mathrm{~h}$ half of the 


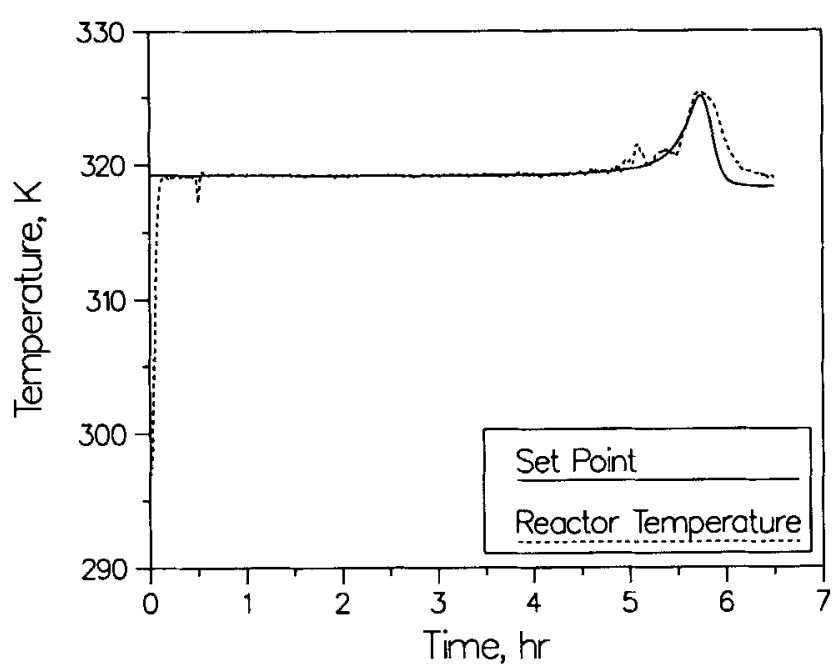

Figure 11a. Profiles of the set point and reactor temperature (case IV).

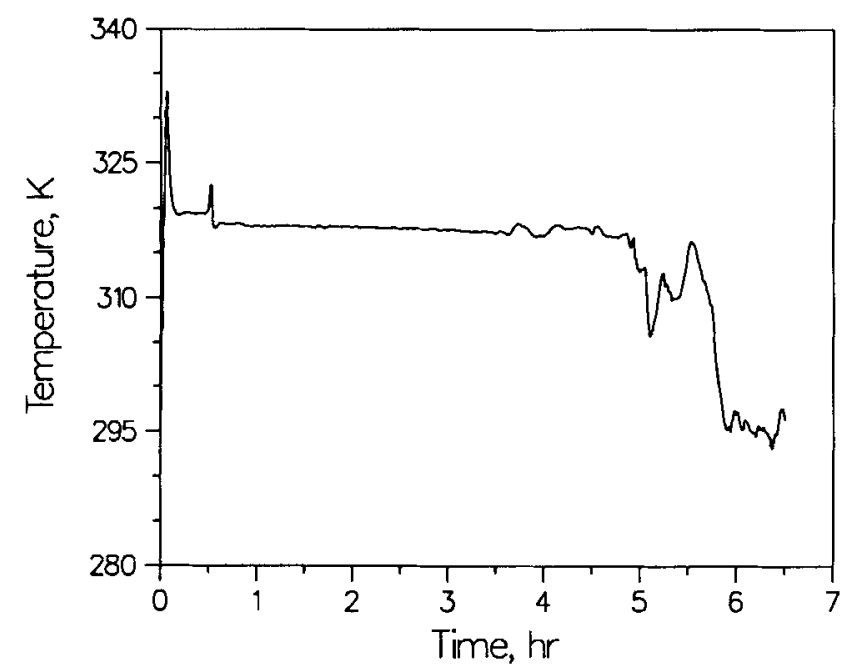

Figure 11b. Jacket temperature profile corresponding to Figure 11a.

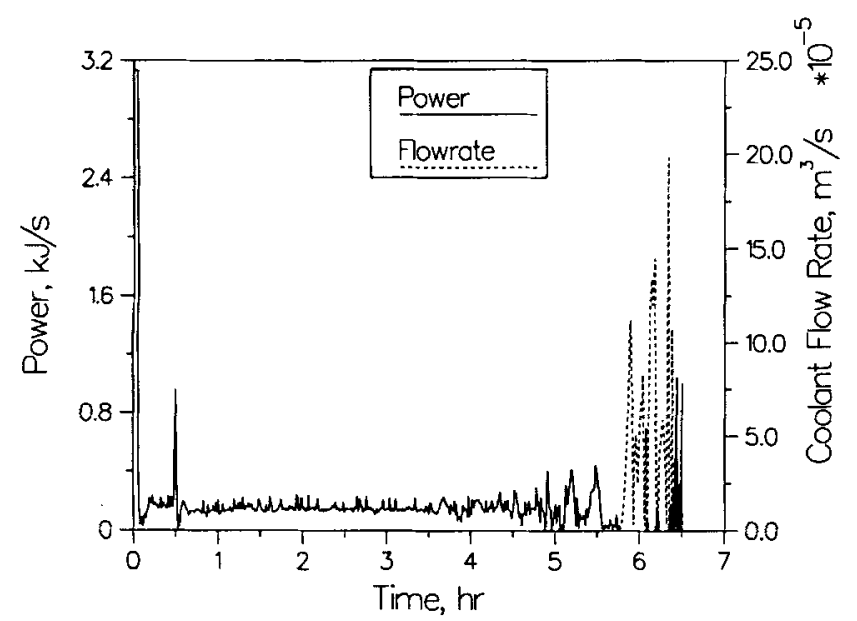

Figure 11c. Profiles of the cooling water flow rate and heater power corresponding to Figure 11a.

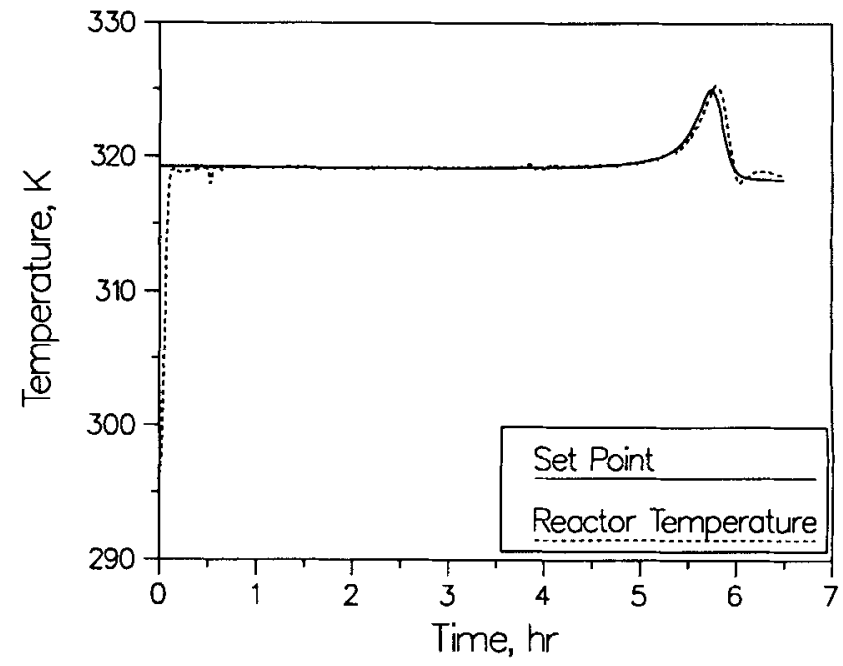

Figure 12a. Profiles of the set point and reactor temperature (case V).

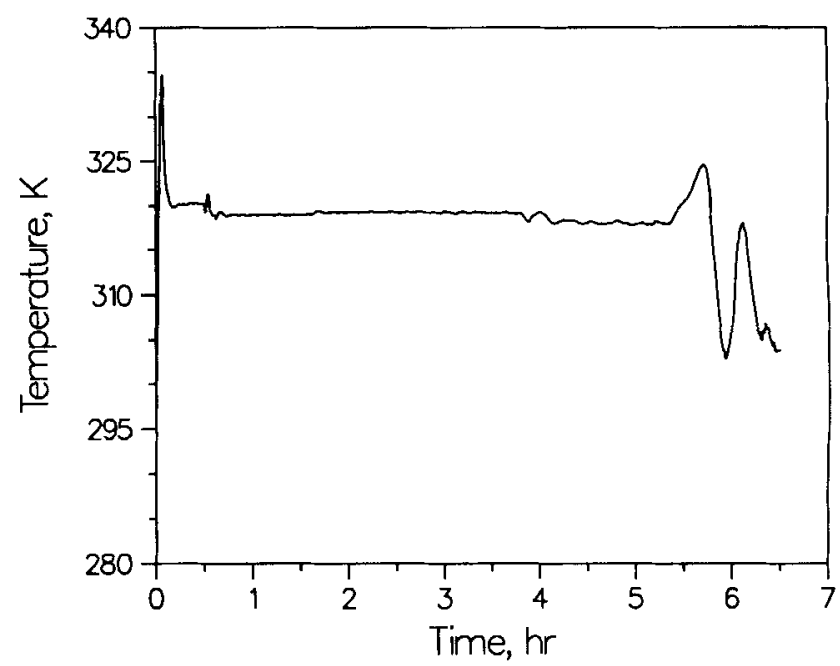

Figure 12b. Jacket temperature profile corresponding to Figure 12a.

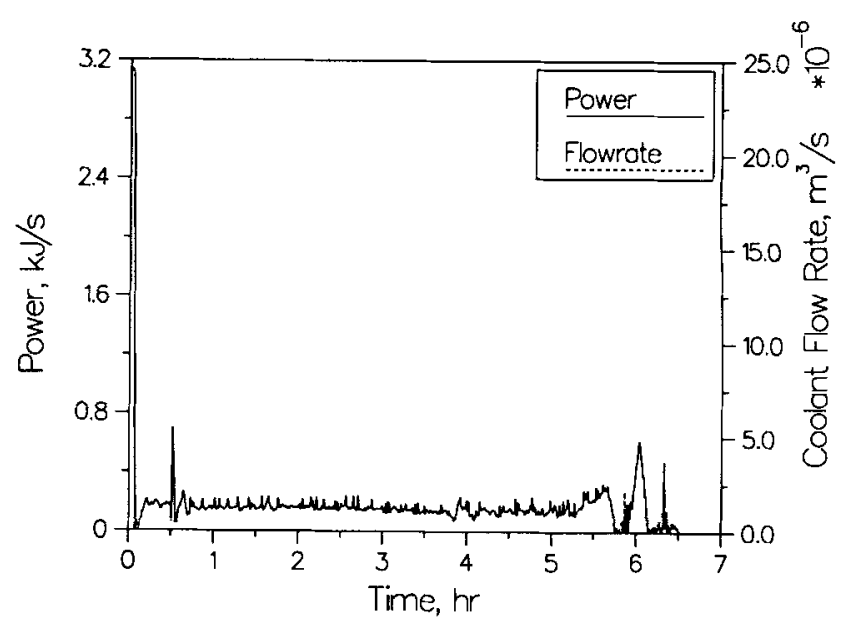

Figure 12c. Profiles of the cooling water flow rate and heater power corresponding to Figure 12a. 


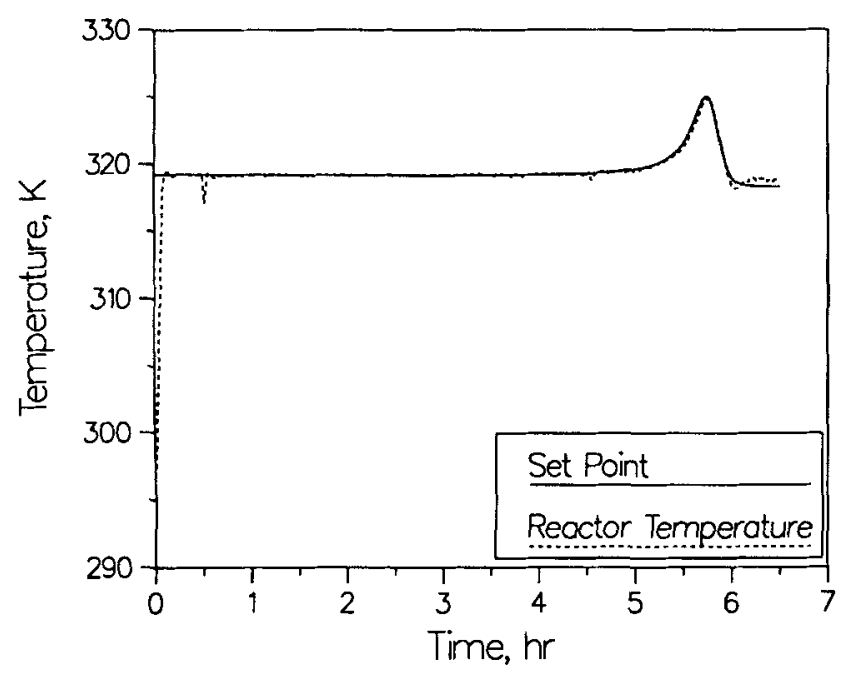

Figure 13a. Profiles of the set point and reactor tem. perature (case VI).

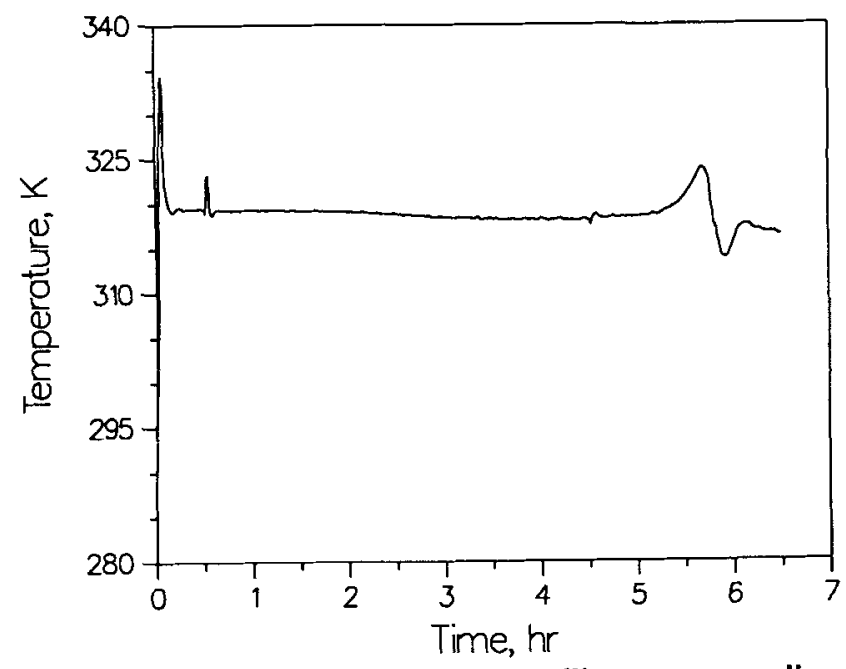

Figure 13b. Jacket temperature profile corresponding to Figure 13a.

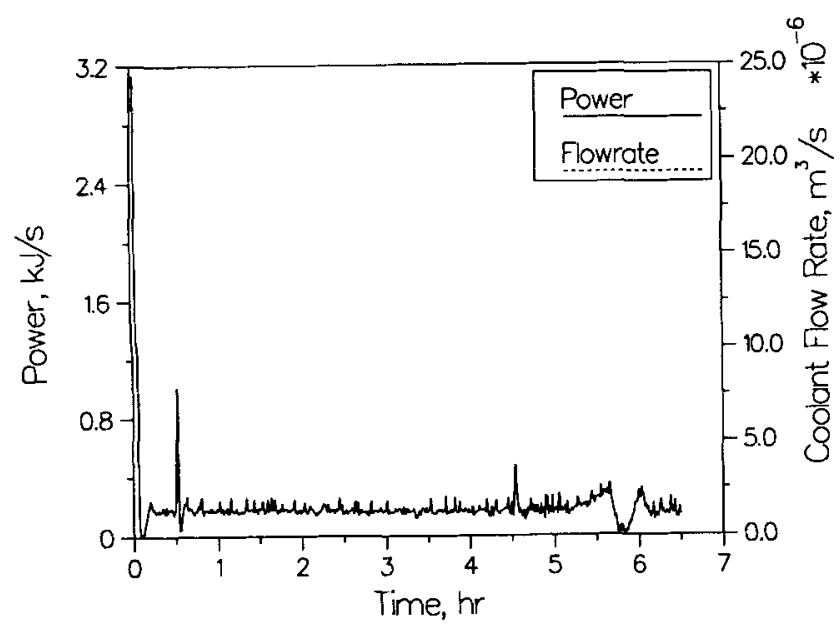

Figure 13c. Profiles of the cooling water flow rate and heater power corresponding to Figure 13a. optimal amount of initiator is loaded. Figure $12 \mathrm{a}$ depicts the reactor temperature for this case. This figure shows that even under $50 \%$ error in initiator loading, the controller can track the set point very satisfactorily. Note that the controller behaves based on the assumption that full optimal amount of the initiator is loaded at $t=0$. This shows the significant robustness of the controller against the errors in initialization of the state observer and therefore errors in the state estimation. Under these conditions, the temperature profile $T^{*}(t)$ is no longer optimal. The gravimetric results show a final conversion of $0.57\left[x_{m}(6.5)=0.57\right]$, while the on-line calculated value of conversion by the model is $x_{m}(6.5)=0.99$ (which is calculated by the model under the initial conditions corresponding to the optimal loading conditions). Figures $12 \mathrm{~b}$ and $12 \mathrm{c}$ depict the corresponding jacket temperature and the actual manipulated variable profiles.

\section{Case VI: PI-bias $=T^{*}(t), U=U_{0}, A=A_{0}$, and no nitro- gen bubbling}

This case is similar to case IV, but oxygen is not purged from the reactor (presence of oxygen which is an inhibitor, in the system) by nitrogen bubbling. Figure $13 \mathrm{a}$ depicts the reactor temperature for this case. This figure shows that even under the presence of inhibitor in the system (significant error in the kinetic model) the controller can track the set point very satisfactorily. Since the existence of the inhibitor in the system is not included in the model, this modeling error causes a significant discrepancy between the observer estimates and the actual values of the states. However, the results show the significant robustness of the controller to modeling errors in the reaction kinetics. As in case $\mathrm{V}$, the temperature profile $T^{*}(t)$ is no longer optimal in the present case. The gravimetric results show a final conversion of $0.34\left[x_{m}(6.5)=0.34\right]$, while the on-line calculated value of conversion by the state observer is $x_{m}(6.5)=0.99$. Figures $13 \mathrm{~b}$ and $13 \mathrm{c}$ depict the corresponding jacket temperature and the actual manipulated variable profiles.

The experimental results of cases II, IV, V and VI show the robustness of the controller to observer initialization and modeling errors. Note that the better performance of the controller in cases $\mathrm{V}$ and VI is due to the fact that both of the errors (the initiator loading error and the presence of oxygen in the reactor) are in the direction of producing less viscous mixture toward the end of the batch.

Case VII: PI-bias $=T^{*}(t), U=U_{0}, A=A_{0}$, loading error and disturbance

This case is similar to case IV, but only $78 \%$ of cold monomer solution is loaded initially at $t=0$. The remaining $22 \%$ of the cold monomer solution is loaded at $t=3.5 \mathrm{~h}$. Although, from a polymerization point of view, this case may not be interesting; however, it illustrates the regulatory performance of the controller and also its robustness to another form of observer initialization errors. Figure 14a depicts the reactor temperature for this case. As can be seen from this figure, the controller immediately eliminates the effect of the disturbance on the temperature at $t=3.5 \mathrm{~h}$ (that is, the controller immediately returns the reactor temperature to its set point without overshoot). This figure also shows that even under the presence of the initialization errors, the controller exhibits excellent servo 


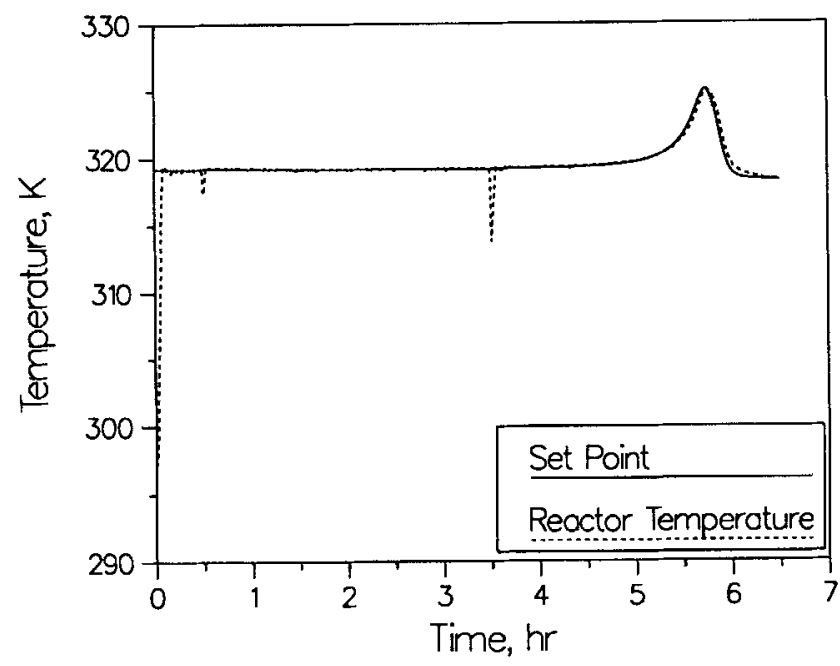

Figure 14a. Profiles of the set point and reactor temperature (case VII).

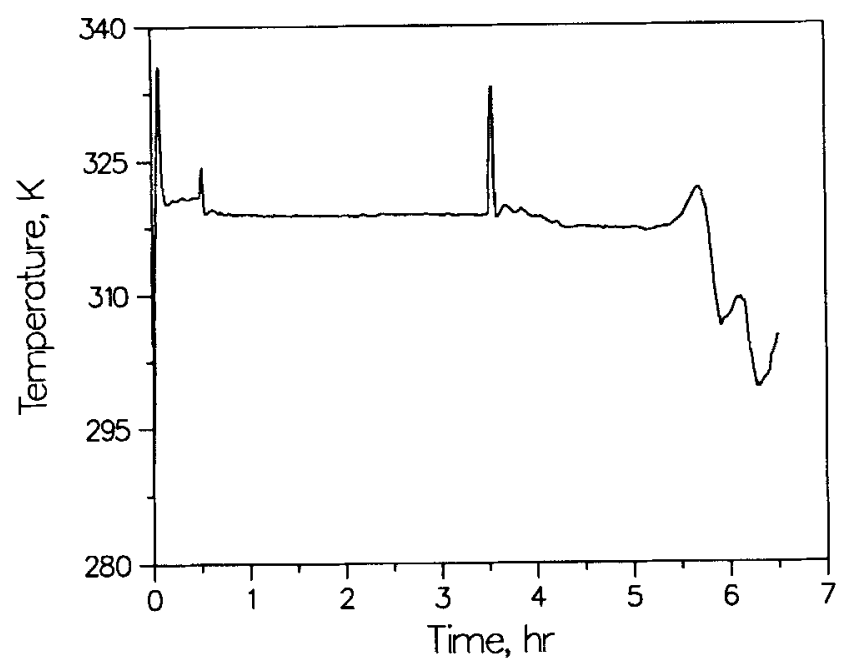

Figure 14b. Jacket temperature profile corresponding to Figure 14a.

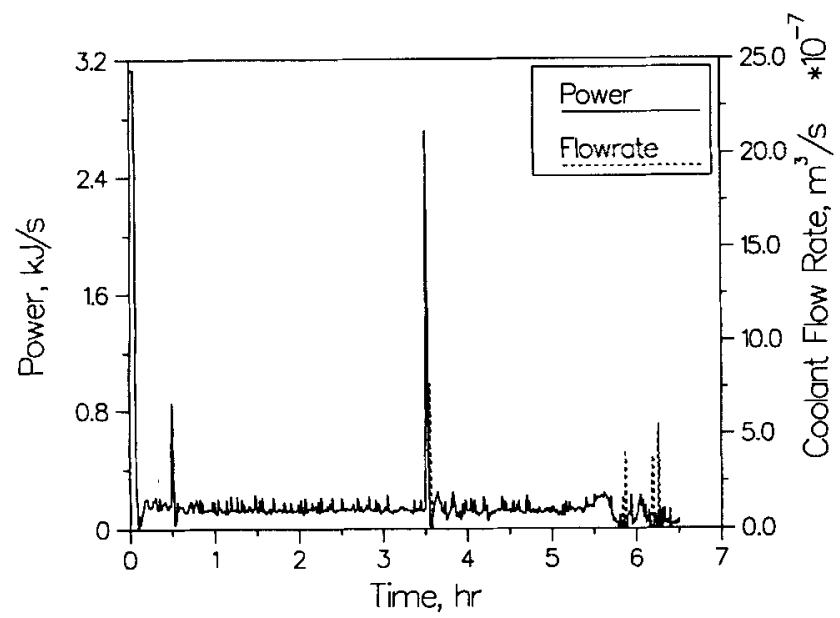

Figure 14c. Profiles of the cooling water flow rate and heater power corresponding to Figure $14 a$.

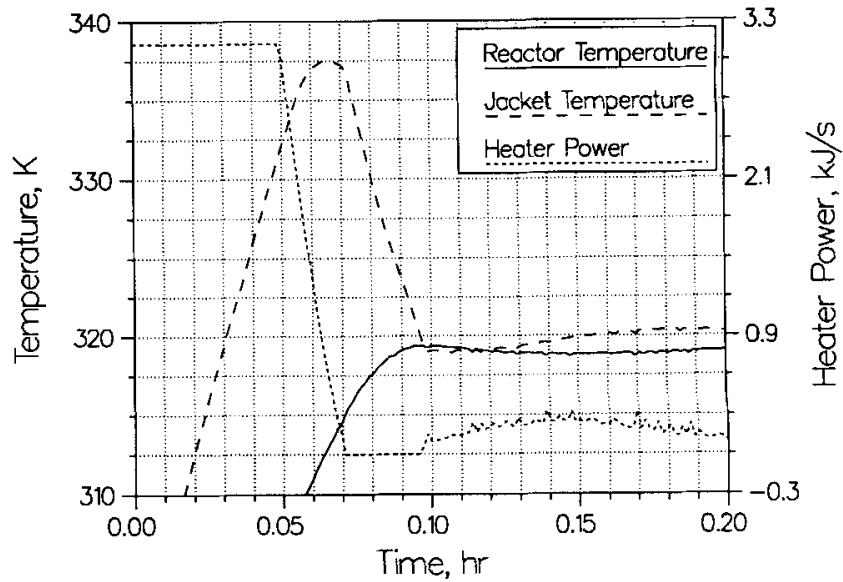

Figure 15. Magnified picture of start-up profiles of the run for case $\mathbf{I}$.

and regulatory performance. Figures $14 \mathrm{~b}$ and $14 \mathrm{c}$ depict the corresponding jacket temperature and the actual manipulated variable profiles. As these figures show, the response of the controller to the disturbance at $t=3.5 \mathrm{~h}$ is very aggressive.

Remark 4. Some of the experimental runs were performed in Winter (runs for cases I, II and VII) and some in Summer (runs for other cases) with the same tuning and process model parameters. The inlet cooling water temperature $T_{c w}$ was $6.5^{\circ} \mathrm{C}$ in Winter while $T_{c w}$ was $18^{\circ} \mathrm{C}$ in Summer. As indicated in Table 1 , the nominal value of $T_{c w}=6.5^{\circ} \mathrm{C}$ was used in all the experimental runs. The experimental results show that a significant error in $T_{c w}$ does not affect the controller performance.

Remark 5. The behavior of the controller during the period of startup, shown in Figure 15 (that is, maximum heating, cooling and finally small amount of heating), resembles the behavior of a bang-bang controller. If the start-up of the batch reactor is formulated as an optimal control problem (that is, finding the manipulated input profile which takes the reactor temperature to its set point as fast as possible), then one obtains a bang-bang controller with similar behavior. The use of a bang-bang controller for the startup of batch reactors has been proposed by Shinskey and Weinstein (1965) through the use of a dual-mode controller. The dual-model controller consists of two controllers: (a) a bang-bang controller for startup; (b) a PID controller for the period after the startup.

Remark 6. The effect of the choice of PI bias and the model for $U$ and $A$ on the controller performance can be intuitively justified as follows:

- Using the bias $v_{b}(t)$ as given by Eq. 22 makes the controller anticipate future changes in the set point and therefore "plan ahead," instead of acting after the fact. This explains the improvement in the controller performance during the last hour of the batch cycle (after the maximum of the set-point trajectory).

- Using $U_{0}$ and $A_{0}$ represents a huge error in the heat-transfer rate toward the end of the batch. This makes the controller "think" that it has a much higher heat-transfer rate and therefore act less aggressively toward the end of the batch (see also Eq. 20, where the denominator of the control law is proportional to $U A$ ). This explains the deterioration in the controller performance during the last hour of operation, especially in the run for case IV. 


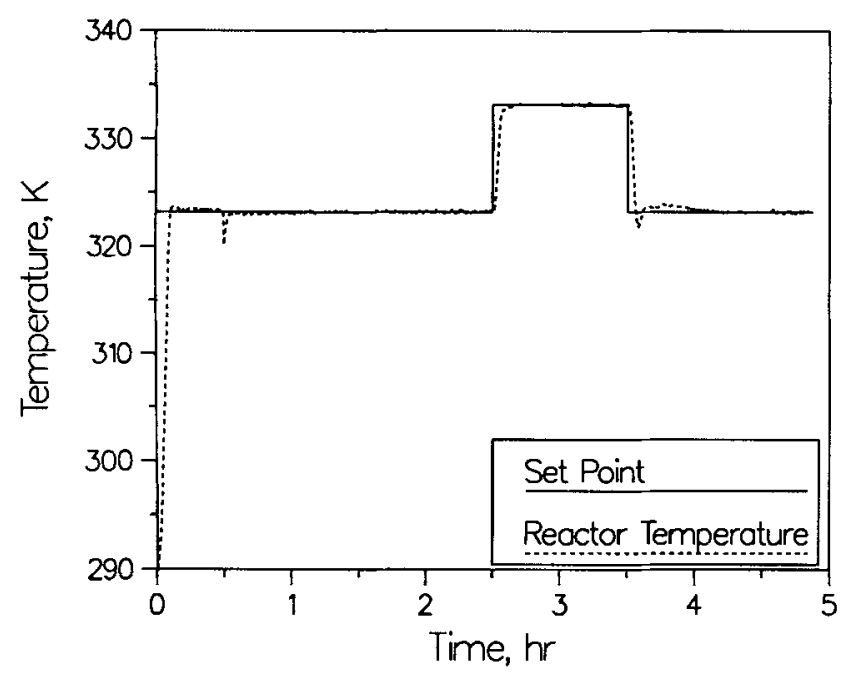

Figure 16a. Profiles of the set point and reactor temperature (case VIII).

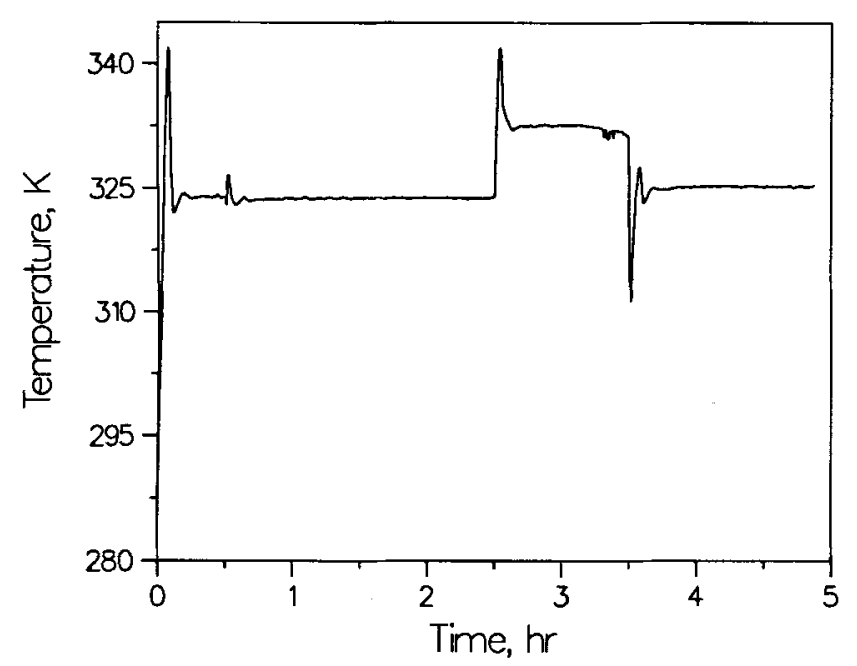

Figure 16b. Jacket temperature profile corresponding to Figure 15 a.

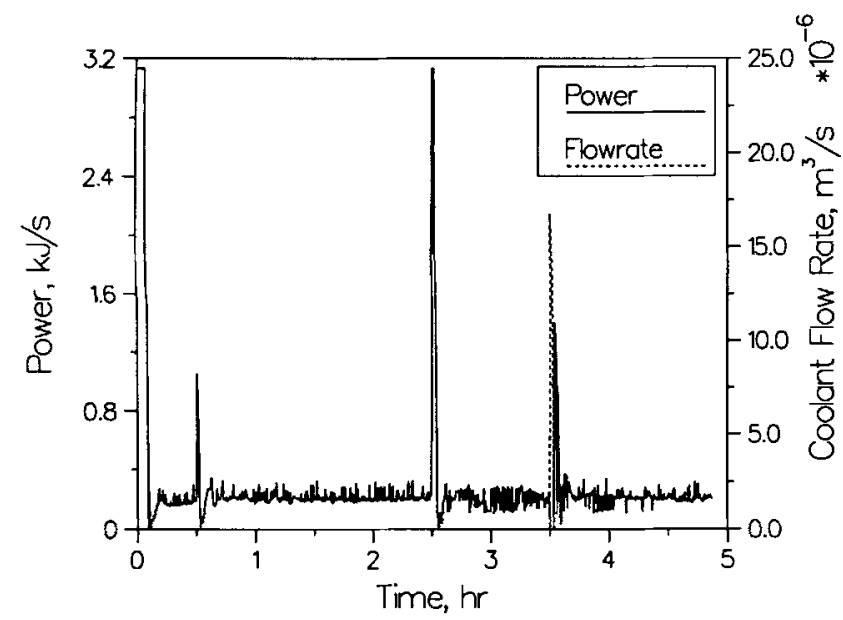

Figure 16c. Profiles of the cooling water flow rate and heater power corresponding to Figure 15a.
Case VIII: $U=U_{0}, A=A_{0}$, step changes in the set point

The objective in this case is to study the performance of the nonlinear controller in tracking step changes in the set point, rather than the optimal operating profile of the reactor. This case is similar to case IV, but the set point $T_{s p}(t)$ is not the optimal temperature profile $T^{*}(t)$. Here, the set point is:

$$
T_{s p}(t)= \begin{cases}323.2 \mathrm{~K}, & 0 \leq t<2.5 \mathrm{~h}, \\ 333.2 \mathrm{~K}, & 2.5 \leq t<3.5 \mathrm{~h}, \\ 323.2 \mathrm{~K}, & 3.5 \leq t \leq 5.0 \mathrm{~h}\end{cases}
$$

that is, there are two-step changes in the set point, first at $t=2.5 \mathrm{~h}$ from $323.2 \mathrm{~K}$ to $333.2 \mathrm{~K}$, and second at $t=3.5 \mathrm{~h}$ from $333.2 \mathrm{~K}$ to $323.2 \mathrm{~K}$. In this case, the set point profile $T_{s p}(t)$ is used as the PI bias, and the reactor is loaded with the optimal amounts of monomer and initiator. Figure 16a depicts the set point and reactor temperature for this case; it shows the ability of the controller in tracking step changes in the set point. Figures $16 \mathrm{~b}$ and $16 \mathrm{c}$ depict the corresponding jacket temperature and the actual manipulated variable profiles. As these figures show, the initial response of the controller to the step changes consists of two distinct aggressive actions: (a) an action to take the process to the new set point value as fast as possible; (b) a second action in the opposite direction of the first one to prevent overshoot.

\section{Case IX: PID controller}

To compare the performance of the nonlinear controller with a conventional controller, a digital PID controller in the form:

$$
\begin{aligned}
u\left(t_{k}\right)=u\left(t_{k-1}\right)+K_{c} & {\left[\left(1+\frac{\Delta t}{\tau_{I}}+\frac{\tau_{D}}{\Delta t}\right) e\left(t_{k}\right)\right.} \\
& \left.-\left(1+2 \frac{\tau_{D}}{\Delta t}\right) e\left(t_{k-1}\right)+\frac{\tau_{D}}{\Delta t} e\left(t_{k-2}\right)\right]
\end{aligned}
$$

where $e\left(t_{k}\right)=T^{*}\left(t_{k}\right)-T\left(i_{k}\right)$, is used with the tuning parameters $K_{c}=0.05 \mathrm{~kJ} \cdot \mathrm{s}^{-1} \cdot \mathrm{K}^{-1}, \tau_{l}=1,000 \mathrm{~s}$ and $\tau_{d}=0.1 \mathrm{~s}$. These parameter values are the best values that could be obtained by trial and error. Once $u\left(t_{k}\right)$ is calculated by Eq. 27, the same coordination rules (Eqs. 10 and 11) are used to calculate corresponding values of the coolant flow rate $\left[F_{c w}\left(t_{k}\right)\right]$ and heater power $\left[\boldsymbol{P}\left(t_{k}\right)\right]$. Note that under the PID controller, the manipulated input $u$ never hits any constraint; therefore, the integrator of the PID is always active. Figure 17a depicts the set point and the reactor temperature under PID control. As can be seen from this figure, the PID controller performed poorly both at the beginning and at the end of the batch cycle. A comparison of the Figures $8 \mathrm{a}, 9 \mathrm{a}, 10 \mathrm{a}, 11 \mathrm{a}$ with Figure 17a shows the superior performance of the GLC compared to a traditional controller. Figures $17 \mathrm{~b}$ and $17 \mathrm{c}$ depict the corresponding jacket temperature and the actual manipulated variable profiles for the PID controller.

\section{Concluding Remarks}

This work provides the first experimental study of a non- 


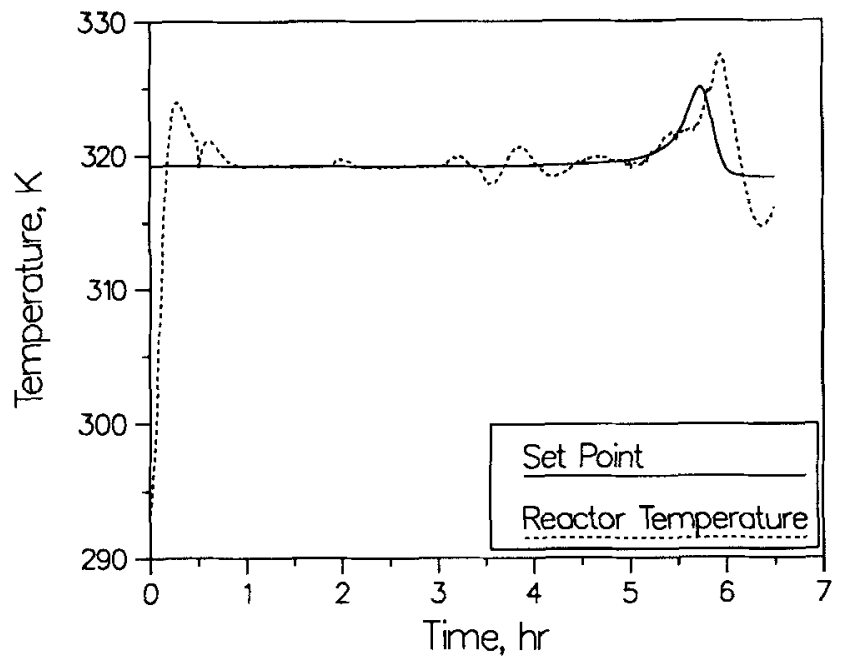

Figure 17a. Profiles of the set point and reactor temperature (case IX: PID).



Figure 17b. Jacket temperature profile corresponding to Figure 17a.

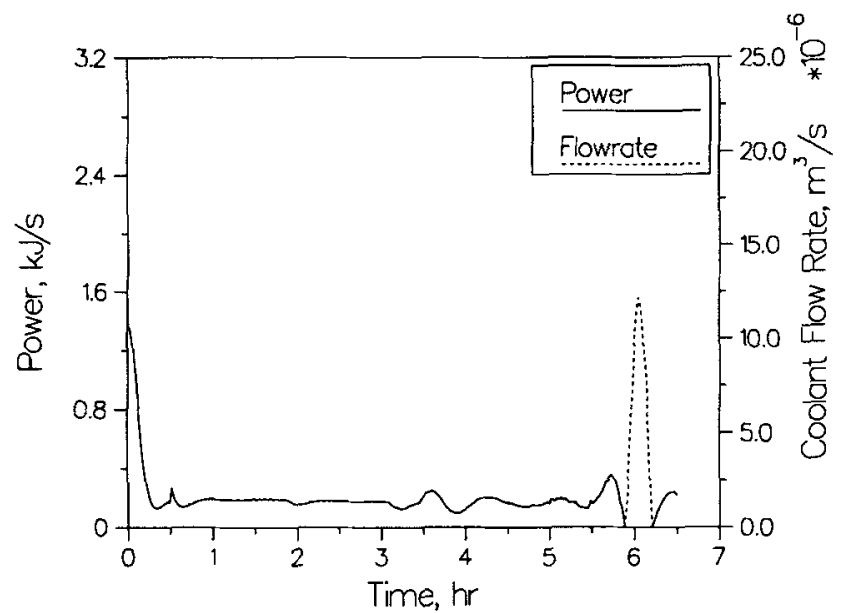

Figure 17c. Profiles of the cooling water flow rate and heater power corresponding to Figure 17a. linear control strategy for a polymerization reactor. The control law was synthesized using the GLC method and systematic tuning guidelines were proposed.

It was seen that by using available mathematical models, a highly nonlinear and complex polymerization process can be effectively controlled. The mathematical model in its "natural form" (set of nonlinear ordinary differential equations), without any approximation or transformation, is incorporated in a systematic and general way in the controller design. Furthermore, the experimental study shows that the nonlinear GLC controller is:

- Very simple to derive and tune

- Computationally efficient so that it can be implemented on a small microcomputer

- Able to cope with input constraints

- Robust with respect to modeling and observer initialization errors.

Moreover, when compared to a conventional PID controller, the superiority of the nonlinear controller becomes very clear both in terms of closed-loop performance and ease of tuning.

\section{Acknowledgment}

Financial support from the National Science Foundation through the grant CTS-8912836 is gratefully acknowledged. The authors wish to thank Robert Zand for his invaluable assistance in the experimental procedures for carrying out the polymerization reaction.

\section{Notation}

$A, A_{\infty}=$ reactor-jacket and surrounding-jacket heat-transfer areas, $\mathrm{m}^{2}$

$A(T)=$ temperature-dependent parameter in gel effect model $B=$ constant parameter in gel effect model

$c=$ heat capacity of reacting mixture, $\mathrm{kJ} \cdot \mathrm{kg}^{-1} \cdot \mathrm{K}^{-1}$

$C_{i}=$ concentration of initiator, $\mathrm{kmol} \cdot \mathrm{m}^{-3}$

$C_{i}(0)=$ loading concentration of initiator, $\mathrm{kmol} \cdot \mathrm{m}^{-3}$

$C_{i}^{*}(0)=$ optimal loading concentration of initiator, $\mathrm{kmol} \cdot \mathrm{m}^{-3}$ $C_{m}=$ concentration of monomer, $\mathrm{kmol} \cdot \mathrm{m}^{-3}$

$C_{m b}, C_{m}(0)=$ loading concentration of monomer, $\mathrm{kmol} \cdot \mathrm{m}^{-3}$

$C_{m}^{*}(0)=$ optimal loading concentration of monomer, $\mathrm{kmol} \cdot \mathrm{m}^{-3}$

$C_{s}=$ concentration of solvent, $\mathrm{kmol} \cdot \mathrm{m}^{-3}$

$c_{\mathrm{w}}=$ heat capacity of water, $\mathrm{kJ} \cdot \mathrm{kg}^{-1} \cdot \mathrm{K}^{-1}$

$D=$ intermediate variable in the gel and glass effect models

$D_{n}=$ dead polymer chain consisting of $n$ monomer units

$E_{i}, E_{P}=$ activation energies for initiation and propagation reactions, $\mathrm{kJ} \cdot \mathrm{kmol}^{-1}$

$E_{f_{m}}=$ activation energy for chain transfer to monomer reactions, $\mathrm{kJ} \cdot \mathrm{kmol}^{-1}$

$E_{P_{0}}, E_{t_{0}}=$ activation energies for the reaction rate constants $k_{P_{0}}$ and $k_{t_{0}}$, respectively, $\mathrm{kJ} \cdot \mathrm{kmol}^{-1}$

$E_{\theta_{t}}, E_{\theta_{p}}=$ activation energies for the parameters $k_{\theta_{i}}$ and $k_{\theta_{p}}$, respectively, $\mathrm{kJ} \cdot \mathrm{kmol}^{-1}$

$f=$ initiator efficiency

$F_{c w}=$ inlet flow rate of cooling water, $\mathrm{m}^{3} \cdot \mathrm{s}^{-1}$

$F_{\mathrm{cw}^{\prime} \max }=$ maximum inlet flow rate of cooling water, $\mathrm{m}^{3} \cdot \mathrm{s}^{-1}$

$I=$ initiator

$K_{c}=$ gain of the external controller

$k_{f_{m}}, k_{p}=$ rate constants for chain transfer to monomer and propagation reactions, $\mathrm{m}^{3} \cdot \mathrm{kmol}^{-1} \cdot \mathrm{s}^{-1}$

$k_{t_{c}}, k_{t_{d}}=$ rate constants for termination by combination and disproportiation reactions, $\mathrm{m}^{3} \cdot \mathrm{kmol}^{-1} \cdot \mathrm{s}^{-1}$

$k_{t}=k_{t_{d}}+k_{t_{c}}, \mathrm{~m}^{3} \cdot \mathrm{kmol}^{-1} \cdot \mathrm{s}^{-1}$

$k_{P_{0}}, k_{t_{0}}=$ overall propagation and termination rate constants at zero monomer conversion, $\mathrm{m}^{3} \cdot \mathrm{kmol}^{-1} \cdot \mathrm{s}^{-1}$

$k_{i}=$ rate constant for initiation reaction, $\mathrm{s}^{-1}$

$k_{\theta_{p}}=$ temperature-dependent parameter in gel effect model 


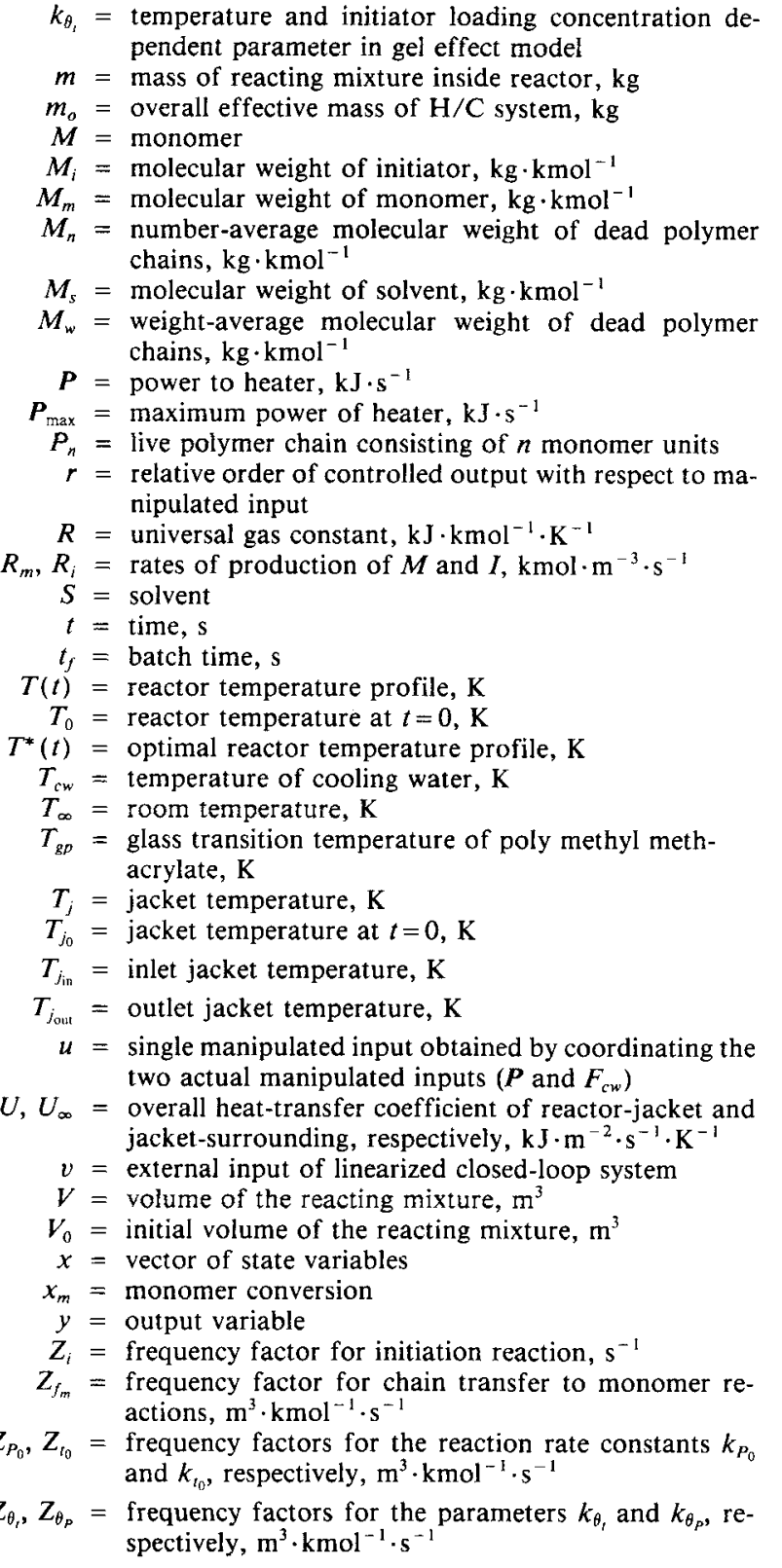

\section{Greek letters}

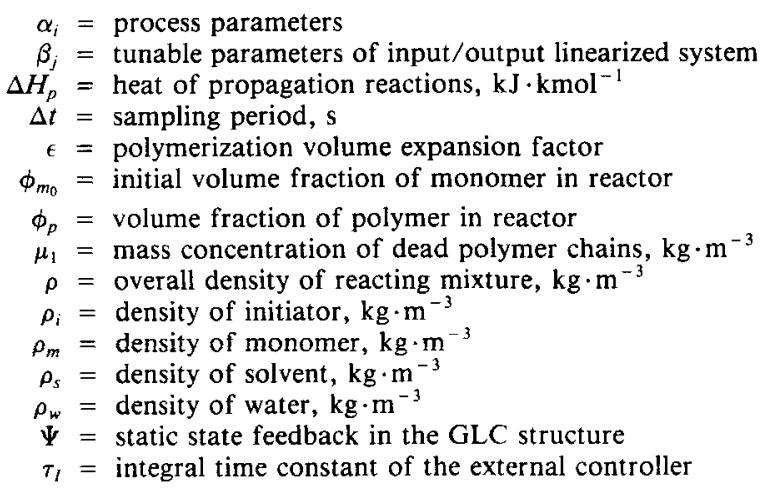

\section{Math symbols}

$$
\begin{aligned}
\triangleq & =\text { is defined } \\
\epsilon & =\text { belongs to } \\
\mathbb{R} & =\text { real line }
\end{aligned}
$$

$L_{f} h(x)=$ Lie derivative of the scalar field $h(x)$ with respect to the vector field $f(x)$

$L_{f}^{r-1} h(x)=(r-1)$ th-order Lie derivative of the scalar field $h(x)$ with respect to the vector field $f(x)$

$L_{g} L_{f}^{r-1} h(x)=$ Lie derivative of the scalar field $L_{f}^{r-1} h(x)$ with respect to the vector field $g(x)$

\section{Acronyms}

AIBN $=$ azo-bis-isobutyronitrile

GLC = globally linearizing control

LCH = long chain hypothesis

MMA = methyl methacrylate

$\mathrm{MWD}=$ molecular weight distribution

PDI $=$ polydispersity index

PI = proportional-integral

PID = proportional integral derivative

QSSA = quasi-steady-state approximation

SISO $=$ single-input single-output

\section{Literature Cited}

Amrehn, H., "Computer Control in Polymerization Industry," $A u$ tomatica, 13, 533 (1977).

Baillagou, P. E., and D. S. Soong, "Major Factors Contributing to the Nonlinear Kinetics of Free-Radical Polymerization," Chem. Eng. Sci, 40(1), 75 (1985a).

Baillagou, P. E., and D. S. Soong, "Molecular Weight Distribution of Products of Free Radical Nonisothermal Polymerization with Gel Effect. Simulation for Polymerization of Poly(methylmethacrylate)," Chem. Eng. Sci., 40(1), 87 (1985b).

Bejger, T. P., M. V. Tirrell, and G. Stephanopoulos, "Batch Copolymerization: Self-Tuning Optimization and Control," AIChE Meeting, New Orleans (1981).

Chiu, W. Y., G. M. Carratt, and D. S. Soong, "A Computer Model for the Gel Effect in Free-Radical Polymerization," Macromol. 16(3), 348 (1983).

Chylla, R. W., and D. R. Haase, "Temperature Control of Semibatch Polymerization Reactors," AIChE Meeting, Chicago (Nov., 1990).

Collins, E. A., J. Bares, and F. W. Billmeyer, Experiments in Polymer Science, p. 333, Wiley, New York (1973).

Daoutidis, P., and C. Kravaris, "Dynamic Output Feedback Control of Minimum-Phase Nonlinear Processes," Chem. Eng. Sci., 47, 837 (1992).

Daoutidis, P., M. Soroush, and C. Kravaris, "Dynamic Output Feedback Control of Multivariable Nonlinear Processes," AIChE Meeting, Los Angeles (1991).

Elicabe, G. E., and G. R. Meira, "Estimation and Control in Polymerization Reactors. A Review," Poly. Eng. \& Sci., 28, 121 (1988).

Hamer, J. W., T. A. Akramov, and W. H. Ray, "The Dynamic Behavior of Continuous Polymerization Reactors-II," Chem. Eng. Sci., 36, 1879 (1981).

Inglis, M. P., W. R. Clurtt, and A. Penlidis, "Long Range Predictive Control of a Polymerization Reactor," Can. J. of Chem. Eng., 69, 120 (1991).

Juba, M. R., and J. W. Hamer, "Progress and Challenges in Batch Process Control," Chemical Process Control-CPC III, p. 139, M. Morari and T. J. McAvoy, eds. (1986).

Jutan, A., and A. Uppal, "Combined Feedforward-Feedback Servo Control Scheme for an Exothermic Batch Reactor," Ind. Eng. Chem. Process Des. Res., 23, 597 (1984).

Kravaris, C., and C. B. Chung," "Nonlinear State Feedback Synthesis by Global Input/Output Linearization," AIChE J., 33, 592 (1987).

Kravaris, C., and M. Soroush, "Synthesis of Multivariable Nonlinear Controllers by Input/Output Linearization," AIChE J., 36, 249 (1990).

Levine, J., and P. Rouchon, "Quality Control of Binary Distillation Columns via Nonlinear Aggregated Models," Automatica, 27, 463 (1991).

MacGregor, J. F., "Control of Polymerization Reactors," Proc. of IFAC, 31 (1986).

Nakamoto, K., and N. Watanabe, "Multivariable Control Experiments of Nonlinear Chemical Processes Using Non-linear Feedback Transformation," J. Proc. Cont., 1, 140 (1991). 
Nijmeijer, H., and A. J. van der Schaft, Nonlinear Dynamical Control Systems, p. 176, Springer-Verlag (1990).

Ponnuswamy, S. R., S. L. Shah, and C. A. Kipparissides, "Computer Optimal Control of Batch Polymerization Reactors," Ind. Eng. Chem. Res., 26, 2229 (1987).

Ray, W. H., "On the Mathematical Modeling of Polymerization Reactors," J. Macromolec. Sci-Revs. Macromol. Chem., C8(1), 1 (1972).

Ray, W. H., "Polymerization Reactor Control," IEEE Cont. Systs. Mag., 6(4), 3 (1986).

Ray, W. H., "Modeling and Control of Polymerization Reactors," Proc. IFAC Symp. on Dynamics and Control of Chemical Reactors, Distillation Columns and Batch Processes, p. 161, College Park, MD (1992).

Rivera, D. E., M. Morari, and S. Skogestad, "Internal Model Control: 4. PID Controller Design," Ind. Eng. Chem. Process Des., 25, 252 (1986).

Schmidt, A. D., and W. H. Ray, "The Dynamic Behavior of Continuous Polymerization Reactors-I," Chem. Eng. Sci, 36, 1401 (1981).

Schmidt, A. D., A. B. Clinch, and W. H. Ray, "The Dynamic Behavior of Continuous Polymerization Reactors-III," Chem. Eng. Sci., 39, 419 (1981).

Seborg, D. E., T. F. Edgar, and D. A. Mellichamp, Process Dynamics and Control, p. 526, Wiley, New York (1989).

Shinskey, F. G., and J. L. Weinstein, "A Dual Mode Controller System for a Batch Exothermic Reactor," ISA Conf., Los Angeles (Oct. 4-7, 1965).

Smith, C. A., and A. B. Corripio, Principles and Practice of Automatic Process Control, p. 240, Wiley, New York (1985).

Soroush, M., and C. Kravaris, "Nonlinear Control of a Batch Polymerization Reactor," Proc. ACC, p. 2879, Boston (1991).

Soroush, M., and C. Kravaris, "Optimal Design and Operation of Batch Reactors: 2. a Case Study," Ind. Eng. Chem. Res., in press (1992a).

Soroush, M., and C. Kravaris, "Discrete-Time Nonlinear Controller Synthesis by Input/Output Linearization," AIChE J., in press (1992b).

Soroush, M., "Studies in Nonlinear Control and Optimal Design with Experimental Application to Polymerization Reactors," PhD Thesis, The University of Michigan (1992).

Takamatsu, T., S. Shioya, Y. Okada, and M. Uchiyama, "Application of an Adaptive Controller to Molecular Weight Distribution Control in a Batch Polymerization Process," Proc. IFAC, Munich, p. 227, FRG (1987).

Tirrell, M., R. Galvan, and R. L. Laurence, "Polymerization Reactors," Chemical Reaction and Reactor Engineering, J. J. Carberry and A. Varma, eds., Marcel Dekker, Basel-New York (1987).

Tirrell, M., and K. Gromley, "Composition Control of Batch Copolymerization Reactors," Chem. Eng. Sci, 36, 367 (1981).

Tzouanas, K. V., and S. L. Shah, "Adaptive Pole-Assignment Control of a Batch Polymerization Reactor," Chem. Eng. Sci., 5, 1183 (1989).

Wright, R. A., M. Soroush, and C. Kravaris, "Strong Acid Equivalent Control of pH Processes: An Experimental Study," I\&EC Res., 30, 2437 (1991).

\section{Appendix: Calculation of $\boldsymbol{v}_{b}(t)$}

The procedure involves the following steps:

Calculation (approximation) of $\left[d^{2} T^{*}(t)\right] / d t^{2}$. Passing the profile $T^{*}(t)$ through the differentiator-filter (lead-lag filter);

$$
\frac{s^{2}}{\left(\epsilon_{d} s+1\right)^{2}}
$$

which has the minimal-order state-space realization:

$$
\begin{aligned}
\dot{z}_{1} & =z_{2}, & z_{1}(0)=0 \\
\dot{z}_{2} & =\frac{-1}{\epsilon_{d}^{2}} z_{1}+\frac{-2}{\epsilon_{d}} z_{2}+\frac{1}{\epsilon_{d}^{2}}\left[T^{*}(t)-T^{*}(0)\right], & z_{2}(0)=0 \\
\frac{d^{2} T^{*}(t)}{d t^{2}} & \approx \frac{-1}{\epsilon_{d}^{2}} z_{1}+\frac{-2}{\epsilon_{d}} z_{2}+\frac{1}{\epsilon_{d}^{2}}\left[T^{*}(t)-T^{*}(0)\right] &
\end{aligned}
$$

that is, numerically integrating the above two differential equations while using $T^{*}(t)$ as input, we obtain the approximate profile of the 2 nd derivative of $T^{*}(t)$.

Calculation (approximation) of $\left[d T^{*}(t)\right] / d t$. Passing the profile through the differentiator-filter (lead-lag filter):

$$
\frac{s}{\epsilon_{d} s+1}
$$

which has the minimal-order state-space realization:

$$
\left\{\begin{array}{c}
\dot{z}_{1}=\frac{-1}{\epsilon_{d}} z_{1}+\frac{1}{\epsilon_{d}}\left[T^{*}(t)-T^{*}(0)\right], \quad z_{1}(0)=0 \\
\frac{d T^{*}(t)}{d t} \approx \frac{-1}{\epsilon_{d}} z_{1}+\frac{1}{\epsilon_{d}}\left[T^{*}(t)-T^{*}(0)\right]
\end{array}\right.
$$

that is, numerically integrating the above differential equation while using $T^{*}(t)$ as input, we obtain the approximate profile of the 1st derivative of $T^{*}(t)$.

In this study, the value of $\epsilon_{d}=0.01$ gives both satisfactory differentiation accuracy and noise suppression.

Once the approximate profiles of $\left[d^{2} T^{*}(t)\right] / d t^{2}$ and $\left[d T^{*}(t)\right] / d t$ are calculated, then

$$
v_{b}(t)=T^{*}(t)+\beta_{1} \frac{d T^{*}(t)}{d t}+\beta_{2} \frac{d^{2} T^{*}(t)}{d t^{2}}
$$

is computed.

Manuscript received Feb. 10, 1992, and revision received May 26, 1992. 